San Jose State University

SJSU ScholarWorks

Master's Theses

Master's Theses and Graduate Research

1993

\title{
Thermoregulatory effects of caffeine ingestion during rest and exercise in men
}

Nancy A. Dunagan

San Jose State University

Follow this and additional works at: https://scholarworks.sjsu.edu/etd_theses

\section{Recommended Citation}

Dunagan, Nancy A., "Thermoregulatory effects of caffeine ingestion during rest and exercise in men" (1993). Master's Theses. 536.

DOI: https://doi.org/10.31979/etd.h3jt-53xf

https://scholarworks.sjsu.edu/etd_theses/536

This Thesis is brought to you for free and open access by the Master's Theses and Graduate Research at SJSU ScholarWorks. It has been accepted for inclusion in Master's Theses by an authorized administrator of SJSU ScholarWorks. For more information, please contact scholarworks@sjsu.edu. 


\section{INFORMATION TO USERS}

This manuscript has been reproduced from the microfilm master. UMI films the text directly from the original or copy submitted. Thus, some thesis and dissertation copies are in typewriter face, while others may be from any type of computer printer.

The quality of this reproduction is dependent upon the quality of the copy submitted. Broken or indistinct print, colored or poor quality illustrations and photographs, print bleedthrough, substandard margins, and improper alignment can adversely affect reproduction.

In the unlikely event that the author did not send UMI a complete manuscript and there are missing pages, these will be noted. Also, if unauthorized copyright material had to be removed, a note will indicate the deletion.

Oversize materials (e.g., maps, drawings, charts) are reproduced by sectioning the original, beginning at the upper left-hand corner and continuing from left to right in equal sections with small overlaps. Each original is also photographed in one exposure and is included in reduced form at the back of the book.

Photographs included in the original manuscript have been reproduced xerographically in this copy. Higher quality $6 "$ " 9 9" black and white photographic prints are available for any photographs or illustrations appearing in this copy for an additional charge. Contact UMI directly to order.

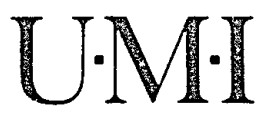

University Microfilms International 

Order Number 1853013

Thermoregulatory effects of caffeine ingestion during rest and exercise in men

Dunagan, Nancy Alaine, M.A.

San Jose State University, 1993 



\title{
THERMOREGULATORY EFFECTS OF CAFEEINE INGESTION DURING REST AND EXERCISE IN MEN
}

\author{
A Thesis \\ Presented to \\ The Faculty of the Department of Human Performance \\ San Jose State University
}

In Partial Fulfillment

of the

Requirements for the Degree

Masters of Arts

By

Nancy A. Dunagan

May, 1993 
APPROVED FOR THE DEPARTMENT OF HUMAN PERFORMANCE

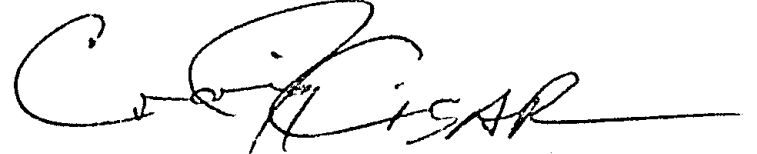

Dr. Craig Cisar

$$
\text { W.R. Hofoont }
$$

Dr. William Holcomb

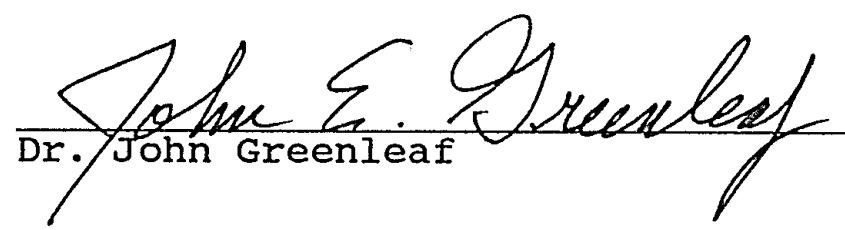

APPROVED BY THE UNIVERSITY

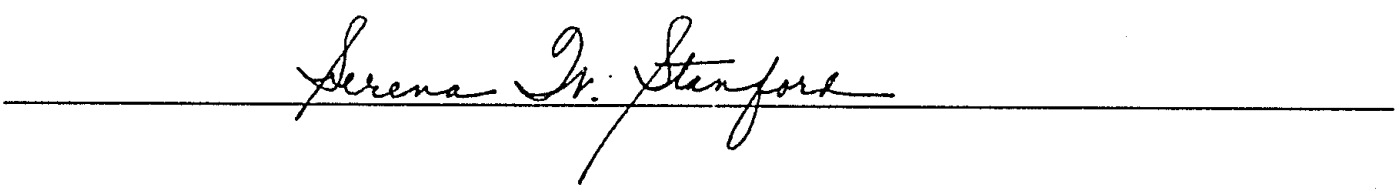




\section{THERMOREGULATORY EFFECTS OF CAFFEINE INGESTION \\ DURING REST AND EXERCISE IN MEN.}

N. A. Dunagan

Thermoregulatory responses were measured at rest and during submaximal exercise in normal ambient conditions in 11 men with (CT) and without (NCT) the ingestion of $10 \mathrm{mg}$ of caffeine/kg of body weight. After ingestion of caffeine or a placebo, data were collected throughout 30 minutes of rest and the following 70 minutes of leg ergometer exercise $(\sim 68 \%$ of $V 02 \max )$. There were no significant differences $(p<.05)$ between NCT and CT in oxygen uptake, heart rate, rectal or skin temperatures, or skin heat conductance (2way ANCOVA), or between NCT and $\mathrm{CT}$ in sweat rate (t-test). Thus, a high level of caffeine ingestion has no detrimental effects on body temperature responses during heavy exercise in normal ambient conditions. 
I dedicate this thesis to my husband, Stephen E. Dunagan, who inspired me to greater achievement and supported me in my process toward that goal. 


\section{ACKNOWLEDGMENTS}

This past Thanksgiving morning I awoke about 5:00 a. m. with the thoughts racing through my head of all the help I have received during the long journey of conceiving, doing, analyzing, and writing this study. Dr. Craig Cisar has always been available and helpful throughout this long process. During the long early hours of data collection Dr. Cisar was there. The assistance and direction Dr. Cisar gave was invaluable, and I sincerely appreciate the help he has given.

In the beginning, when the light went on, when the idea for this thesis was being formed, Dr. John Greenleaf at NASA AMES Research Center was willing to listen to this graduate student whom he had never seen or heard of before. During those discussions my ideas were molded and changed to form the ultimate plan. Dr Greenleaf has given much of his time and expertise to this research. Without his help I know this study would have been very different and may never have been accomplished.

Before data collection started I knew I would need large quantities of donated labor. Five technicians were needed for each trial, and each of the twelve volunteers went through three trials. I received a tremendous amount of help from friends, associates, and strangers willing to donate time and help as lab technicians. Al Christensen 
was one of those friends. Al donated many hours of his time and assisted with every testing session. Not only did Al assist with about every type of data collection that occurred, but he was invaluable to me as a time keeper. He wrote a computer program that we used for keeping track of time and for data entry. The hours and genuine interest that Al gave to this project went far beyond what one expects from a friend, and I am deeply grateful to Al for the help he gave me.

As I mentioned earlier, this study could not have been done without the help of many friends, associates and strangers. By the end of data collection I considered all those who had helped out as friends. There where too many technicians to elaborate on each's contribution, but the following friends were of invaluable worth to me as lab technicians: Stephanie Adams, Leslie Bostick, Bonita Christensen, Mike Cole, Carlos Crownover, Jan Finger, Constance Honeychurch, Richard Devirt, JoAnne Gilleland, Tacy Hahn, Mindy Hansen, Susie Leary, Karen Marshall, Virginia Mendoza, Terri Oberg, Adrienne Robinson, Derek Tiefer, and Ken VanAalsburg. I am sure someone slipped through the cracks and I didn't get their name down, but these people monitored heart rates, temperatures, fans, workloads, and in general created a pleasant atmosphere within which to work. 
Although I can't mention their names, the subjects in this study not only went through all kinds of discomforts, but they were fun to be around. This was quite an accomplishment in the early hours of the morning when a lot of this data collection was taking place.

While I was laying in bed those early hours on Thanksgiving many other people drifted in and out of my thoughts. People who had contributed to my whole educational and research experience. I had to share the physiology lab with Terri wexted during those data collection months and Terri was very cooperative in working together with me. Minera Duke, a good friend and mentor, kept planting seeds of inspiration that enabled the idea of going back to school for a Masters degree to grow.

My children have lived through this experience with me. Meghan was three when I started, and is now in first grade. Christian was in kindergarten, and is now in third grade. Both have provided lots of hugs and pats on the back when I realiy needed those hugs and pats.

My husband, steve, has been the ultimate guinea pig. Before data collection could begin I had to learn what I was doing, which means I had to practice on someone. Well, Steve has always "been there" for me, and this thesis business was no exception. From beginning to end Steve has been a good sounding board, and his scientific and 
educational background have pulled me through some of the harder times during this learning experience. For all your help, Steve, I say thanks. You're just my speed.

viii 
Table of Contents

CHAPTER

Page

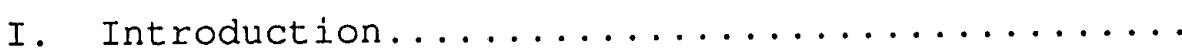

Background for the study............ 1

statement of the Purpose........... 5

Approach to the Problem........... 5

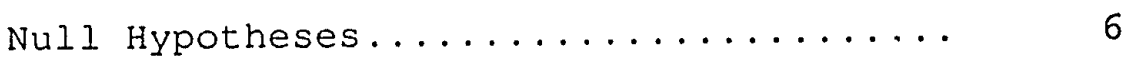

Delimitations.................. 6

Limitations................... 7

Assumptions................. 7

Definitions.................. 8

Significance of the Problem......... 11

II. REVIEW OF IITERATURE................ 12

Introduction................. 12

Consumption of Caffeine........... 12

Physiological Effects of Caffeine...... 12

General Factors Involved in

Thermoregulation............... 15

Effects of Caffeine on Thermoregulation. 16

Summary and Conclusion............ 26

III. METHODS..................... 30

Int roduction................ 30

subjects.................. 30

Measurements and Methods........... 31 


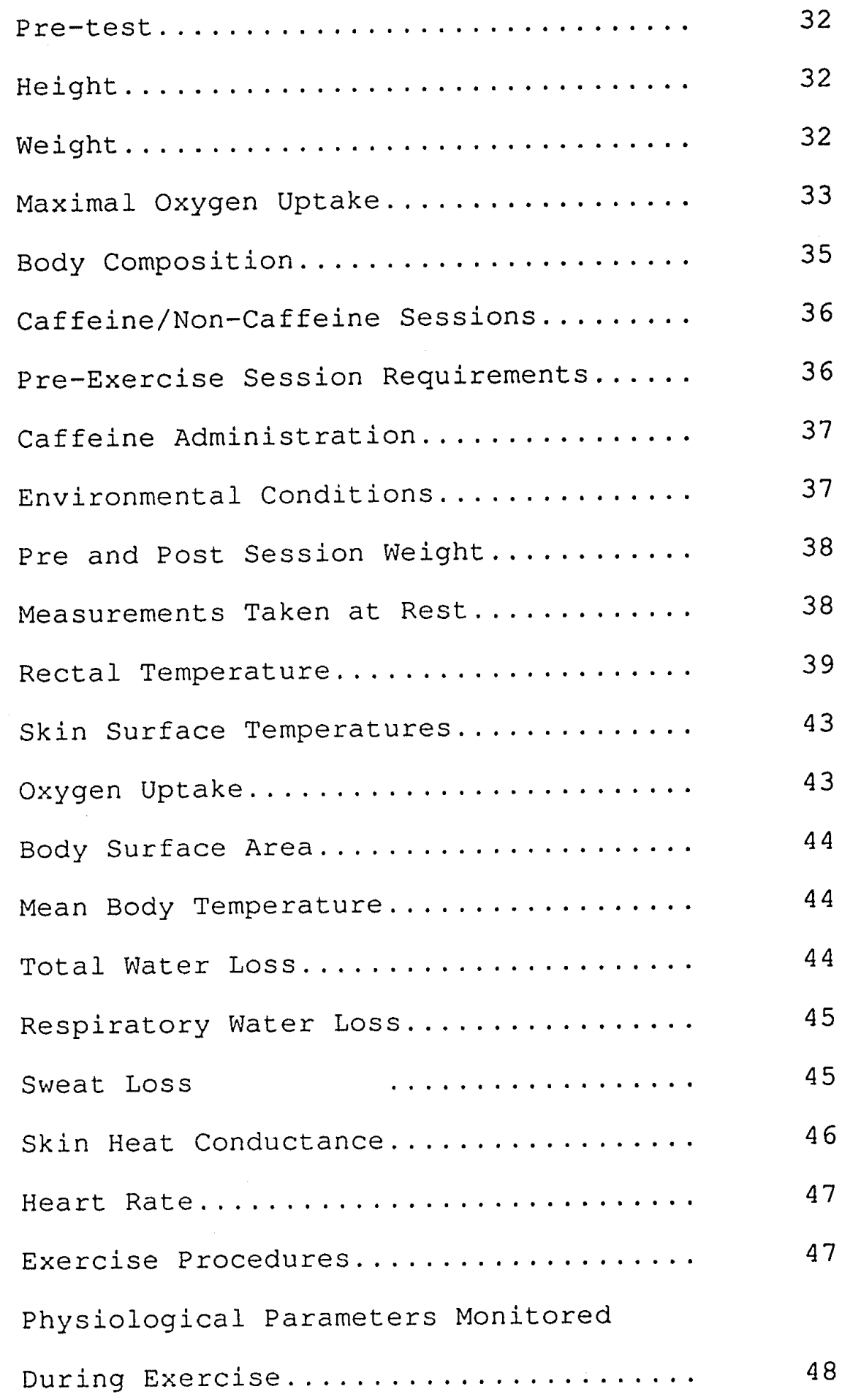


IV. Data Analysis.................... 50

Introduction................ 50

Level of Significance............ 50

Analysis of data.............. 50

Summary of Findings............. 61

Discussion of Findings............ 63

Conclusion................. 66

Weaknesses.................. 66

Recommendations for Euture Research.... 67

REFERENCES....................... 68 
A. Health Questionnaire........... 79

B. Statement of Informed Consent..... 82

C. Residual Lung Volume and Underwater Weighing Data Sheet.... 87

D. List of Caffeine Sources........ 88

E. Advertisement to Solicit Subjects.. 89

F. Data Collection Sheets........... 90

G. Two-Way Analysis of Covariance

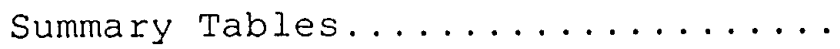

H. Summary Tables for Selected

Caffeine Research............. 
1. Anthropometric and Physiological Data........ 52

2. Ambient Temperature Data............... 52

3. Weight and Sweat Loss Data During

Caffeine and Control Test............... 52

4. Physiological Data during Caffeine

and Control Test..................

Figures

1. Electrode and Thermistor Placement.......... 40

2. Thermistor Placement................ 41

3. Experimental set Up................. 42

4. Oxygen Uptake..................... 55

5. Mean Heart Rate................... 55

6. Mean Rectal Temperature............... 56

7. Mean Rectal Temperature Differences......... 56

8. Mean Skin Temperature................ 58

9. Mean Skin Temperature Differences........... 58

10. Skin Heat Conductance................ 59 


\section{CHAPTER I}

\section{Introduction}

Chapter one presents the background information, statement of the purpose, null hypotheses, delimitations, limitations, operational definitions, significance of the problem, and the statistical analysis for this investigation.

\section{Background Information}

Caffeine has long been used for its aileged capability to uplift attitude, decrease fatigue, and increase work capacity (Rall, 1985). Only 50 milligrams of caffeine will evoke physiological responses involving the digestive system, the central nervous system, and the cardiovascular system (Somani \& Gupta, 1988). Because of caffeine's possible ergogenic effects on athletic competition, the International Olympic Cominittee plasma caffeine concentrations to less than $15 \mathrm{ug} / \mathrm{ml}$ (Rosenbloom \& Sutton, 1985).

Caffeine has been reported to either improve endurance capabilities (Chad \& Quigley, 1989; Costill, Dalsky, \& Fink, 1978; McNaughton, 1986; Sasaki, Maeda, Usui, \& Ishiko, 1987) or to have no effect on aerobic performance (Aragyasami, Yang, \& Winder, 1989; Bond, Adams, Balkisson, McRae, Knight, Ribbins, \& Banks, 1987; Falk et al. 1989; 
Tarnopolsky, Atkinson, MacDougall, Sale, \& Sutton, 1989; Winder, 1986). Athletes continue to take caffeine before competition although data concerning caffeine's effectiveness as an ergogenic aid has been disparate. Because caffeine is so commonly ingested in situations which tax the thermoregulatory system, caffeine's effect on thermoregulation should be addressed.

There are several pharmacological effects of caffeine which could possibly cause shifts in temperature regulation. Caffeine increases urinary water and sodium secretion (O'Neil, Hynak-Hanbison, \& Gordan, 1986). Thus caffeine may decrease the available fluid and electrolytes which are necessary for maintenance of body fluid volumes and evaporative and convective cooling. Caffeine also stimulates metabolic rate (Dullo \& Miller, 1986; Dullo, Geissler, Horton, Collins, \& Miller, 1989; Jequier, 1987; and LeBlanc, Jobin Cote, Samson, \& Labrie, 1985). If the heat generated from the higher metabolic rate is not released through thermoregulatory avenues (convection, radiation, conduction, or evaporation), heat storage (and therefore body temperature) would ultimately be increased. Caffeine's effect on the cutaneous vascular system is unclear. Several authors (Beckman, 1961; Govoni \& Hayes, 1978; Kastrup, 1984) have attributed peripheral vasodilation to caffeine consumption. Cutaneous vasodilation would enhance internal heat dissipation via 
conductance (Sawka, 1988). However, Robertson and Curatolo (1984) indicated that caffeine induces a pressor response by potentiating the effect of catecholamines on smooth muscle and actually increasing catacholamine release in most individuals. Epinephrine and norepinephrine constrict many arterioles, especially those in the skin (Schottelius \& Schottelius, 1978), which would result in decreased heat dissipation by lowering conductance and evaporative heat loss. The stimulating effect of caffeine on the sympathetic nervous system and cardiovascular system may also play an important role in human temperature regulation: "Drugs that affect the cardiovascular and central nervous systems, either directly or via the autonomic nervous system, can have important implications for the maintenance of normal thermoregulation" (Rosenbloom \& Sutton, 1985, p. 177). Caffeine's effect on temperature regulation is beginning to receive scientific attention. Lin, Chandron, and Liu (1980) and Schlosberg (1983) found that caffeine produced hyperthermic responses in rats placed in normal and hot environments. Human subjects experienced less of a temperature decrease in a cold environment when given an ephedrine (1 $\mathrm{mg} / \mathrm{kg})$ and caffeine $(2.5 \mathrm{mg} / \mathrm{kg})$ mixture, but caffeine's exclusive effect on temperature regulation was unclear (Valerand, Jacob, \& Kavanagh, 1989). 
Research findings indicate caffeire may have a positive effect, negative effect, or no effect on temperature regulation. Starkenstein (1927) found a xanthine derivative (Diuretin) to increase extrarenal excretion in a steam environment. This additional water loss via perspiration could give short-term beneficial evaporative cooling to the body. But xanthines may produce dehydration under long-term heat exposures, ultimately putting stress of the thermoregulatory system. During sitting rest in heated conditions Biren, Al-Refaee, Finck, and Paolone (1992) found that skin temperatures and oxygen uptake increased with caffeine ingestion, which would normally result in heat storage (Pandolf, Sawka, \& Gonzalez 1988). However, rectal temperature remained constant, most likely due to skin vasodilation, causing higher skin temperatures, thereby increasing heat conductance from the core to the skin.

Caffeine appears to have no effect on thermoregulation during exercise in cold environments (Doubt \& Hsieh, 1991; Graham, Sathasivan, \& MacNaughton, 1991). Graham et al. (1991) found a dose of $5 \mathrm{mg}$ caffeine/kg body weight produced a significant increase in rectal temperature when subjects performed sub-maximal exercise during head-out water $\left(28^{\circ} \mathrm{C}\right)$ immersion.

Falk et al. (1990) found ingested caffeine produced 
tendencies toward greater sweat rate $(\underline{p}<.07)$ and higher

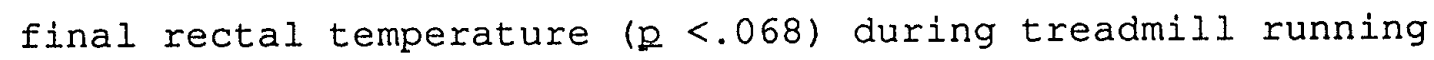
to exhaustion under normal ambient conditions. Five ml caffeine/kg caused no significant difference in rectal temperature at the completion of a two hour run (Gordon et al., 1982), but 2 of the 10 subjects reached rectal temperatures $>40^{\circ} \mathrm{C}$. Athletes often ingest caffeine prior to exercise, either inadvertently or specifically for its alleged ergogenic effects. Since many endurance competitions are performed in environments that tax the body's temperature regulating capabilities, the effect of caffeine on thermoregulation should be further addressed.

\section{Statement of the Purpose}

The purpose of this study was to determine if caffeine affects thermoregulatory factors such as rectal temperature, skin temperature, skin heat conductance, and sweat loss in active men at rest and when preforming intensive sub-maximal aerobic exercise under normal ambient conditions.

\footnotetext{
Approach to the Problem

After pre-test measurements of height, weight, percentage body fat, and maximal oxygen uptake rate were
} 
collected, 12. aerobically conditioned males $(20$ - 41 years of age) underwent a non-caffeine control trial (NCT) and a caffeine trial (CT) (10 mg caffeine per $\mathrm{kg}$ body weight) in normal ambient conditions. Rectal temperature, skin temperatures, oxygen uptake, and heart rate where recorded during 30 minutes of rest followed by 70 minutes of cycle ergometry exercise at approximately $68 \%$ of $\mathrm{VO}_{2} \max$. Total weight loss was determined from the subjects pre-drink weight (plus weight of ingested liquid) and their weight taken directly after the post-exercise cool-down period. Skin heat conductance, mean body temperature, mean skin temperature, and total sweat loss were calculated. Mean 10 minute values were analyzed using repeated measures twoway analyses of covariance. Weight loss and sweat loss were analyzed using dependent $t$-tests.

\section{Nul1 Hypotheses}

There will be no significant differences found between the caffeine and non-caffeine trials in rectal temperature, mean skin temperature, skin heat conductance, or total sweat loss.

\section{Delimitations}

This study was limited to 12 healthy male volunteers ranging in age from 20 to 41 years. The subjects had less 
than $18 \%$ body fat and all had been exercising aerobically at least three times per week for 30 minutes per session prior to testing.

\section{Limitations}

Factors in this study that could not be controlled included:

1. Variations in the genetic makeup of the subjects and their reaction to caffeine.

2. Slight temperature and humidity variations within the testing room.

3. Changes in the fitness level of the subjects during the testing period.

\section{Assumptions}

Assumptions made for this research included:

1. Subjects gave their best effort during the maximum oxygen uptake test and during the two test trials.

2. Subjects complied with dietary restrictions.

3. Subjects maintained their fitness level throughout the two-week experimental period.

4. Subject's heat acclimation status did not change during the study. 
Definitions

The following definitions will be used in this study: Catecholamines: The class of chemicals which includes epinephrine and norepinephrine (Astrand \& Rodahl, 1986).

conduction: Heat exchange between two solid surfaces that are in direct contact. The rate of conductance is directly related to the temperature differences between the two surfaces and the conductivity of the materials, and inversely related to the distance the heat must travel (Santee \& Gonzalez, 1988).

Convection: Heat exchange that occurs between a surface and a fluid (Santee \& Gonzales, 1988). Skin and air are involved in convection in normal human environmental conditions.

Diaphoretic: An adjective meaning "causing perspiration" (Stein, 1982).

Epinephrine: A hormonal substance released from the adrenal medulla when the body experiences pain, cold, hypotension, hypoglycemia, or hypoxia. Epinephrine causes constriction of many arterioles especially in the skin, mucous membranes, and kidneys; but causes dilation of the coronary system, skeletal muscles, and lungs (Schottelius \& Schottelius, 1978).

Ergogenic: Inclined to increase work output (Astrand \& Rodahl, 1986). 
Evaperative heat less: Moist heat exchange which requires evaporation of water. The physical determinant of evaporative heat loss is the water concentration gradient between the body surface and the environment. The physiological limits depend on sweating rate and the body hydration level (Santee \& Gonzalez, 1988).

Mean body temperature: The average body temperature calculated as the sum of $80 \%$ of the rectal temperature and $20 \%$ of the mean skin temperature (Greenleaf \& Reese, 1980). Metabolic rate: Magnitude of heat production for living animals. Metabolic rate is calculated from oxygen uptake. One liter of oxygen consumed corresponds to approximately $20 \mathrm{~kJ}(4.8 \mathrm{kcal})$ (Astrand \& Rodahl, 1986).

Norepinephrine: The principal chemical transmitter at peripheral sympathetic nerve terminals. Norepinephrine has a vasoconstrictive effect and raises both systolic and diastolic blood pressure (Schottelius \& Schottelius, 1976).

oxygen uptake rate: The volume of oxygen extracted by the body from the inspired air, and is usually expressed in liters of oxygen per minute ( $\mathrm{L} / \mathrm{min})$ or milliliters of oxygen per kilogram of body weight per minute $(\mathrm{mL} / \mathrm{kg} / \mathrm{min})$ (at $0^{\circ} \mathrm{C}, 760 \mathrm{~mm} \mathrm{Hg}$, dry standard temperature and pressure). If the oxygen content of the body remains constant during the measurements, oxygen uptake rate is equivalent to the volume of oxygen utilized from the metabolic oxidation of 
foodstuffs. One liter of oxygen corresponds to 4.7 to 5.05 kcal of energy liberated depending on the proportion of fat and carbohydrate metabolized (Astrand \& Rodahl, 1986).

Pressor: Causing an increase in blood pressure via vasoconstriction (Stein, Hauck \& Su, 1982).

Radiation: A process in which energy is released by one body, transmitted through an intervening medium, and absorbed by another body (Stein et al., 1982). The net radiation balance is determined by calculating the incoming radiation and subtracting the outgoing or emitted radiation (Pandolf et al., 1988).

Rectal temperature: The temperature recorded from the rectum (Pandolf et al., 1988). A probe depth of 16 centimeters was used in this study.

Skin heat conductance: The ratio between the average heat flow to the skin surface and the temperature gradient from the core to the skin surface (Greenleaf \& Reese, 1980)

Skin temperature: In this study, mean skin temperature was calculated relative body surface area using coefficient and temperatures obtained from six skin sites: the upper arm, forearm, chest, back, thigh, and leg. Mean skin temperature $\left(\mathrm{T}_{\mathbf{s k}}\right)$ was calculated as: $0.06\left(\mathrm{~T}_{\mathrm{arm}}\right)+0.13$ $\left(T_{\text {forearm }}\right)+0.19\left(\mathrm{~T}_{\text {chest }}\right)+0.20\left(\mathrm{~T}_{\text {back }}\right)+0.21\left(\mathrm{~T}_{\text {thigh }}\right)+$ 0.21 (Tleg) (Greenleaf \& Castle, 1972). 
Vasodilation: Dilation of the blood vessels (Stein et al., 1982).

Vasoconstriction: Constriction of the blood vessels (Stein et al., 1982).

\section{Significance of the problem}

Athletes often ingest caffeine prior to exercise, either inadvertently or specifically for its ergogenic effects. Since many endurance competitions are performed in hot environments that tax an athlete's temperature regulating capabilities, the effect of caffeine on thermoregulation should be understood. The purpose for this study was to determine if caffeine affects thermoregulatory factors such as rectal temperature, skin surface temperature, skin heat conductance, and sweat rate in active men at rest and when preforming intensive, sub-maximal aerobic exercise within normal ambient environmental conditions. 
CHAPTER II

Review of Literature

Introduction

This chapter will discuss consumption of caffeine, physiological effects of ingested caffeine, general factors involved in thermoregulation, and findings concerning caffeine's effect on body temperature regulation.

\section{Consumption of Caffeine}

Caffeine is ingested freely in today's society. In an excellent review on caffeine Somani and Gupta (1988) identified many caffeine sources. Coffee contains approximately 100 to $150 \mathrm{mg}$ of caffeine per eight ounce cup. Americans average 1.52 cups of caffeine containing beverages a day; however, up to $10 \%$ of America's adult population are believed to consume more than 1,000 $\mathrm{mg}$ of caffeine per day. Caffeine is also found in tea, cocoa, chocolate, cola drinks, approximately 2,000 nonprescription drugs, and over 1,000 prescription drugs.

\section{Physiological Effects of Ingested Caffeine} Caffeine, one of three known methelated xanthine compounds (Power \& Dodd, 1985), and is an alkaloid identified structurally as 1,3,7-trimethylxanthine (Jackobson \& Kulling, 1989). Methylxanthines can be 
absorbed via oral, rectal, or parteneral administration (Powers \& Dodd, 1985). Only 50 milligrams of caffeine can evoke gastric secretion and activation of the central nervous and cardiovascular systems (Somani \& Gupta, 1988). One gram of caffeine (about $6-7$ cups of coffee) can increase respiration and cause insomnia, tachycardia, excitement, ringing in the ears, restlessness, and extra systoles (O'Neil et al., 1986). The acute lethal dose of caffeine for adults is 5 to 10 grams (Rall, 1985).

Orally ingested caffeine is rapidly absorbed through the gastrointestinal tract. Elevated 1,3,7-trimethylxanthine levels can be found in the blood 15 minutes after ingestion and are at peak concentrations 30 to 60 minutes later (Jackobson \& Kulling, 1989). The liver metabolizes caffeine, leaving about $1 \%$ of the caffeine to be recovered in urine (Rall, 1985). The half life of caffeine has been determined to be 3.5 hours (Kastrup, 1984), 2 to 10 hours (Powers \& Dodd, 1985), and 4 to 48 hours (Jackobson \& Kulling, 1989). Varying metabolism with age may explain the large variation.

Caffeine crosses the blood-brain barrier freely and may act directly on the vagal, medullary, and vaso-motor centers (Jackobson \& Kulling, 1989). Every system of the body controlled by the central nervous system may be affected by caffeine (Somani \& Gupta, 1988). Acute pharmacological actions of caffeine include: 
(1) stimulation of the sympathetic nervous system (Rosenbloom \& Sutton, 1985); (2) stimulation of the resting metabolic rate (Jequier, 1987); (3) elevation of plasma epinephrine levels (Bangsbo, Jacobsen, Nordberg, Christensen, \& Graham, 1992; Graham \& Spriet, 1991); (4) increasing jejunal water and sodium secretion (O'Neil et al., 1986); (5) stimulation of cardiac and perhaps skeletal muscle (Powers \& Dodd, 1985); (6) elevation of systolic (Robertson \& Curatolo, 1984) and diastolic blood pressure (Pincomb, Wilson, Hee Sung, Passey, \& Lovallo, 1991); (7) increasing gastric acid secretion (O'Neil et al., 1986); (8) relaxation of smooth muscle (Powers \& Dodd, 1985); and (9) mobilization of free fatty acids (Powers \& Dodd, 1985).

Three cellular mechanisms have been identified to explain caffeine's pharmacological effects. These mechanisms include: 1) the translocation of intracellular calcium, 2) the inhibition of the phosphodiesterase enzyme, and 3) the blocking of adenosine receptors (Powers \& Dodd, 1985). Calcium permeability may be altered by caffeine at the muscle's sarcoplasmic reticulum, resulting in increased $\mathrm{Ca}^{2+}$ release. Phosphodiesterase is a catalyst for the conversion of cyclic AMP to 5'AMP. By decreasing phosphodiesterase, caffeine would indirectly elevate cyclic adenosine monophosphate (cyclic AMP) levels which would result in an increased release of glycerol and free fatty 
acids from triglyceride stores. Adenosine, a component of ATP and nucleic acids, can affect organs via receptors on the cell's surface (Snyder, 1984). Peripherally administered adenosine will constrict bronchi, inhibit platelet aggregation, dilate blood vessels, reduce blood pressure, produce hypothermia, and inhibit the firing of most neurons (Borstel \& Wurtman, 1984; Snyder, 1984). Suppressing adenosine caffeine often causes increases in blood pressure, renin release, catecholamines, and urine output, while simultaneously decreasing bronchial tone (Somani \& Gupta, 1988). Because the concentration of caffeine required to inhibit phosphodiesterase is roughly 100 times that of normal caffeine ingestion, it is more likely that caffeine's molecular mechanism is related to the inhibition of adenosine receptors (Borstel \& Wurtman, 1984; Fernstrom \& Fernstrom, 1984; Snyder, 1984).

\section{General Factors Involved in Thermoregulation} There are many factors that contribute to human thermoregulation. The First Law of Thermodynamics has been used by Santee and Gonzalez (1988) as a basis for measuring the thermal effects of the environment on living organisms. Heat storage (S) involves a balance between internal heat production from metabolism (M), heat exchange that occurs via evaporation (E), conductance (K), convection (C), 
radiation ( $R$ ), and work (W) either leaving the system (-) or by eccentric work $(+)$ done on the system. The heat balance equation, according to santee and Gonzalez (1988) is as follows:

$$
S=M-( \pm W) \pm E \pm R \pm C \pm K \quad\left[W / m^{2}\right]
$$

If the factors on the right side of the equation result in a positive sum for heat storage, the body temperature will increase. Alternatively, if the sum for heat storage is negative, body temperature will decrease. Insight into caffeine's effect on thermoregulation may be enhanced by indentifing its specific effect on any of the heat balance factors. For additional information concerning the mechanisms of thermoregulation, readings from Grayson and Kuehn (1977) or Santee and Gonzalez (1988) are recommended.

\section{Effects of Caffeine on Thermoregulation}

Until recently, little attention has been given to caffeine's effects on the thermoregulatory system. Starkenstein (1927) observed that a xanthine derivative (Diuretin) increased diuretic and diaphoretic (sweating) responses. At room temperature and in a steam bath total water loss (renal and extrarenal) were measured at the end of four hours under the following conditions: (1) without 
water ingestion; (2) with 1 L tap water ingestion; (3) with 1 L of $0.9 \% \mathrm{NaCl}$ solution ingestion; (4) with $2 \mathrm{~g}$ of Diuretin ingestion; and (5) with $1 \mathrm{~L}$ of $0.9 \% \mathrm{NaCl}$ solution $+2 \mathrm{~g}$ Diuretin ingestion. Starkenstein concluded that Diuretin functioned as a weak diuretic at normal room temperature, but Diuretin acted as a diaphoretic in the steam bath.

Rectal temperature was monitored in resting rats during exposure to different ambient temperatures (Iin et al., 1980). Adult male rats were placed in either an 8, 22 , or $30^{\circ} \mathrm{C}$ environment and given 20 minutes to attain thermal balance before being injected intraperitoneal or intraventricular with 10 to $20 \mathrm{mg}$ caffeine/kg. Metabolic rate (calculated from oxygen uptake), respiratory evaporative heat loss (change in water vapor tension of the expired air), and body temperatures (rectal, back skin, foot skin, and tail skin temperatures) were measured each minute for 120 minutes after caffeine injection. In the second phase the rats were pre-treatment with either 6hydroxydopamine (a central catecholaminergic nerve fiber destroyer), phentolamine (blocks alpha-adrenergic receptors), haloperidol (blocks dopaminergic receptors), or propranolol (a B-adrenergic blocker) before caffeine injections. In all environments, caffeine caused a dosedependent increase in rectal temperature, which was 
attributed solely to increased metabolic heat production. Caffeine injections also increased behavioral excitation, cutaneous vasodilation (estimated from higher foot and tail skin temperatures), and diuresis. The hyperthermia due to caffeine injections was attenuated when the rats were pretreated with 6-hydroxydopamine, phentolamine, and haloperidol. In addition to the blockade of alphaadrenergic and dopaminergic receptors, destruction of central catecholaminergic nerve fibers, nullified caffeine's hyperthermic effect. Iin et al. (1980) suggested that "xanthines elicit a central activation of both adrenergic and dopaminergic receptors via release of endogenous noradrenaline and dopamine and lead to behavioral excitation and hyperthermia" (p. 207). The hyperthermic response to caffeine was therefore attributed to increased motor activity, which would result in increased metabolic heat production.

Schlosberg (1983) found that the thermoregulatory response of rats to caffeine was dose dependent and that tolerance to caffeine was rapidly developed. Adult male rats acclimated to an ambient temperature of $22^{\circ} \mathrm{C}$ were used in three experiments. Each protocol used injections of either water or caffeine $(12.5,25,50$, and $100 \mathrm{mg} / \mathrm{kg})$. Experiments one and three were conducted in room temperatures of $21-23^{\circ} \mathrm{C}$; experiment two was conducted in an environmental chamber with temperatures of either 4 or 
$32^{\circ} \mathrm{C}$. In both experiment one and two the acute effects of caffeine on thermoregulation were measured, and in experiment three the effects of daily caffeine administration on thermoregulation over 28 days were measured. Results from experiment one indicated acute caffeine administration produced dose dependent changes in body temperature. The lower caffeine doses $(12.5$ and 25 $\mathrm{mg} / \mathrm{kg}$ ) were followed by hyperthermia. Peak significant temperature increases of $\sim 1^{\circ} \mathrm{C}$ occurred 30 to 60 minutes after caffeine injection, and were no longer significantly different after 2 to 2.5 hours. Conversely, both higher caffeine doses $(50$ and $100 \mathrm{mg} / \mathrm{kg}$ ) induced hypothermia. Maximal decreases in temperature between 1 to $1.5^{\circ} \mathrm{C}$ occurred two hours after caffeine injection. Three and a half hours after injection a $1{ }^{\circ} \mathrm{C}$ deficit was still observed in the rats given 50 and $100 \mathrm{mg} / \mathrm{kg}$ of caffeine.

When the rats in were put in different environmental conditions their body temperature response to caffeine was altered. In the $32^{\circ} \mathrm{C}$ environment there was no hypothermic response to 50 and $100 \mathrm{mg} / \mathrm{kg}$ of caffeine. Although the hyperthermic reactions to 12.5 and $25 \mathrm{mg} / \mathrm{kg}$ of caffeine were less pronounced, there were still significant temperature elevations found when compared to the control group 60 and 90 minutes after injection. When placed in the $4^{\circ} \mathrm{C}$ environment, the rats injected with 50 and $100 \mathrm{mg} / \mathrm{kg}$ 
caffeine continued to have significantly lower body temperatures than the control group. While in the cold environment the $50 \mathrm{mg} / \mathrm{kg}$ dose produced a similar declining body temperature pattern as was observed in the normal ambient environment, the $100 \mathrm{mg} / \mathrm{kg}$ dose produced a drop of almost $4.5^{\circ} \mathrm{C}$ in body temperature after 3.5 hours. Neither of the lower doses of caffeine produced significant changes in body temperature when the rats were exposed to the cold environment. Caffeine dependent alterations in body temperature changed with duration of exposure to the drug. Tolerance to the hypothermic reaction to caffeine developed rapidly. By the 4 th day the high caffeine groups displayed body temperatures no different from the control group. After seven days the $50 \mathrm{mg} / \mathrm{kg}$ group showed a hyperthermic effect which continued for the remaining 28 days. Rats receiving both of the lower caffeine doses continued to display a hyperthermic response throughout the duration of the experiment. These results were attributed to:

(1) possible direct and/or indirect effects on the central and/or peripheral mechanisms involved in thermoregulation; or (2) a secondary effect of physiological and behavioral processes that is unrelated to temperature regulation. This well designed study provided strong evidence that the thermoregulatory response of rats to caffeine is dose and tolerance dependent.

The effects of caffeine ingestion on thermoregulatory 
response during endurance running was observed by Gordon, et al. (1982) in 10 male subjects who had trained together for 17 days. Caffeine consumption was prohibited for 24 hours before the test. The morning of the test all the subjects ingested the same breakfast three hours before the run and, later, 5 subjects were given $5 \mathrm{mg}$ of caffeine/kg orally 1 hour before the run. Rectal temperature was taken before and within 2 minutes of completion of the 2 hour run. The environmental conditions, obtained from a near by weather station, included dry bulb temperatures ranging from $24.5-28.9^{\circ} \mathrm{C}$, wind speed between $17-22 \mathrm{~km} / \mathrm{h}$, and relative humidity of $41-$ $54 \%$. All subjects were given $200 \mathrm{ml}$ of cold water every 20 minutes during the run. Oral caffeine had no significant effect on rectal temperature, plasma volume, or electrolyte levels. Upon completion of the run 2 of the 10 subjects had reached rectal temperatures at the heat stroke threshold $\left(40.6^{\circ} \mathrm{C}\right)$. The rate of temperature elevation was not available since rectal temperature was not monitored throughout the run. Environmental temperature, exercise intensity, fitness level, and caffeine tolerance were additional variables not closely monitored in this study. At the other end of the temperature spectrum, the effect of an ephedrine-caffeine mixture on humans exposed to a cold environment was investigated by valerand et al. 
(1989). Nine adult male subjects underwent two cold exposure tests $\left(10^{\circ} \mathrm{C}\right.$ for three hours) directly after ingesting either a placebo or an ephedrine ( $1 \mathrm{mg} / \mathrm{kg})$ plus caffeine $(2.5 \mathrm{mg} / \mathrm{kg})$ mixture. The subjects fasted 12 hours and refrained from alcohol use at least 48 hours prior to the test. Oxygen consumption and $\mathrm{CO}_{2}$ production were measured during cold exposure in the last 10 minutes of each 30 minute interval. The decreases in core, mean skin, and mean body temperatures were significantly less $(\underline{p}<.01)$ during the ephedrine/caffeine trial when compared with those during the placebo trial. In addition, subjects who received ephedrine/caffeine exhibited greater energy expenditure $(18.6 \%)$ and greater carbohydrate oxidation (41.5\%) compared with placebo results. Heat loss during both trials was the same. Valerand et al. suggested the beneficial effects of the ephedrine/caffeine mixture were due exclusively to greater energy production via enhanced carbohydrate utilization. Because no investigators had established the individual effect of caffeine or ephedrine on cold responses, the separate responses of either drug has not been established.

Since 1990 several investigators have addressed caffeine's effect on thermoregulation. Falk et al. (1990) investigated caffeine's effect on body fluid balance and thermoregulation during treadmill exercise (70-75\% $\left.\mathrm{VO}_{2} \max \right)$ 
performed in a neutral environment $\left(25^{\circ} \mathrm{C}, 50 \circ \mathrm{RH}\right)$. Seven male subjects underwent a placebo trial and a caffeine trial. A dosage of $5 \mathrm{mg}$ caffeine/kg body weight was given 120 minutes prior to exercise, plus an additional $2 \mathrm{mg}$ caffeine/kg body weight was given 30 minutes prior to exercise. Serum caffeine levels during the caffeine trial were $10.74 \pm 0.98 \mathrm{ug} / \mathrm{ml}$ just prior to exercise, $13.07 \pm$ $0.98 \mathrm{ug} / \mathrm{ml}$ after 15 minutes of exercise, and remained constant throughout the remainder of the test. Time to exhaustion was not significantly different between the placebo and caffeine trials $161.60 \pm 9.99$ and $63.91 \pm 6.42$ min, respectively). Mean total water loss $(1,376 \pm 154$ vs $1,141 \pm 158 \mathrm{~mL}$, respectively), sweat rate $(12.4 \pm 1.1$ vs 10 $\pm 0.7 \mathrm{~g} / \mathrm{m}^{2} / \mathrm{min}$, respectively), rise in rectal temperature $\left(2.1 \pm 0.3\right.$ vs. $1.5 \pm 0.4^{\circ} \mathrm{C}$, respectively), and calculated heat storage $(134.4 \pm 17.7$ vs $93.5 \pm 22.5 \mathrm{~W}$, respectively) were not significantly different. Einal rectal temperature, although not significantly different $(p=.068)$, tended to be higher in the caffeine trial. Caffeine may hinder thermoregulation under higher dosages or more stressful conditions because of the observed tendency towards greater water loss with caffeine. The influence of caffeine and exercise on catacholamines and metabolism was observed in 6 men during 2 hours of $5^{\circ} \mathrm{C}$ cold air exposure by Graham, 
Sathasivam, and MacNaughton in 1991. Either a placebo or caffeine ( $5 \mathrm{mg} / \mathrm{kg}$ body weight) capsule was ingested 30 minutes before subjects were exposed to exercise $(60 \mathrm{~W})$ in the cold or exposed to sitting rest in the cold. Rectal temperature, skin temperatures, oxygen consumption, carbon dioxide production, and venous blood samples were taken prior to caffeine or placebo ingestion, and at 5, 30, 60, 90, 120 minutes into cold exposure. Caffeine caused a significantly (86\%) greater increase in plasma epinephrine over the 2-hour period when compared to the placebo trials. Rectal and skin temperatures were not significantly affected by caffeine during any collection times. Because there was no decrease in resting core temperature, environmental conditions may not have been cold enough to produce observable temperature differences. Another study concerning caffeine's effect on thermoregulation with a cold environment was carried out by Doubt and Hsieh in 1991. Four trials were completed using caffeine ( $5 \mathrm{mg} / \mathrm{kg}$ body weight) or a placebo in both cold water $\left(18^{\circ} \mathrm{C}\right)$ and warmer water $\left(28^{\circ} \mathrm{C}\right)$ to observe the possible additive physiological effects of caffeine and cold water during head out immersion ergometer exercise ( $1.5 \mathrm{~W} / \mathrm{kg}$ body weight). Ten male subjects ingested either caffeine or the placebo 90 minutes prior to exercise and immersion conditions. Data were collected starting at immersion and continuing throughout 5 minutes of rest, 5 
minutes of warm up, 55 minutes of exercise, and 15 minutes of recovery. Caffeine increased plasma free fatty acids $(52 \pm 18 \%)$, glycerol $(14 \pm 8 \%)$, lactate $(28 \pm 10 \%)$, as well as oxygen uptake $\left(9 \pm 3 \frac{3}{6}\right)$, minute ventilation ( $\left.7 \pm 5 \%\right)$, heart rate $(4 \pm 1 \%)$, and rectal temperature $(2 \pm .4 \%)$, but had no effect on respiratory exchange ratio in the $28^{\circ} \mathrm{C}$ environment. The increase in rectal temperature was greater $(p<.01)$ with caffeine $\left( \pm 0.78 \pm 0.09^{\circ} \mathrm{C}\right)$ that the placebo $\left(+0.55 \pm 0.15^{\circ} \mathrm{C}\right)$ trials during the $28^{\circ} \mathrm{C}$ exposure. Rectal temperature did not vary significantly during either the caffeine or placebo exposure during the $18^{\circ} \mathrm{C}$ exposure. Mean skin temperature tended to increase with caffeine by 0.1 to $0.2^{\circ} \mathrm{C}$ during both environmental conditions. Caffeine and cold did not have significant additive effects on thermoregulation; but, as stated earlier, caffeine stimulated a rectal temperature increase during the $28^{\circ}$ exposure. The gradient for heat loss was low in the $28^{\circ} \mathrm{C}$ environment compared to the heat production, and vasodilation was insufficient to prevent the increase in core temperature.

Caffeine's effect on body temperature during exposure to a heated $\left(40^{\circ} \mathrm{C}, 70 \% \mathrm{RH}\right)$ and neutral $\left(23^{\circ} \mathrm{C}, 40 \% \mathrm{RH}\right)$ environment studied in 8 male volunteers who took either a placebo, a $4 \mathrm{mg} / \mathrm{kg}$ dose of caffeine, or a $8 \mathrm{mg} / \mathrm{kg}$ dose of caffeine 60 minutes prior to the experimental 
period which consisted of 60 minutes sitting at rest in the neutral or hot air environments (Biren et al., 1992). Oxygen uptake was significantly higher $(p<.05)$ for both caffeine trials when compared to the placebo trial with environment having no effect. Mean skin temperature was significantly higher for both the $4 \mathrm{mg} / \mathrm{kg}$ caffeine trial $\left(34.18 \pm 0.40^{\circ} \mathrm{C}\right)$ and the $8 \mathrm{mg} / \mathrm{kg}$ caffeine trial (34.08 \pm $\left.0.41^{\circ} \mathrm{C}\right)$ compared to the placebo trial $\left(33.84 \pm 0.28^{\circ} \mathrm{C}\right)$. Body core and mean body temperatures were unaffected by cafieine. It was concluded that "the caffeine induced increase in skin temperature reflected an increased conduction of heat from core to shell allowing rectal temperature to be maintained in spite of the drug induced metabolic increase" (p. S63).

\section{Summary and cenclusion}

A summary table of selected caffeine studies is found in Appendix H. Schlosberg (1983) found caffeine affected rat thermoregulatory responses during mild and extreme temperature conditions. Lower levels of caffeine produced a consistent hyperthermic effect throughout the 28 day experiment, whereas the high doses of caffeine initially produced hypothermic responses. After several days the high caffeine doses resulted in either a reduction or no change in temperatures. Thus, results indicated caffeine 
may have positive, negative, or no effect on temperature regulation.

Starkenstein (1927) found a xanthine derivative (Diuretin) to increase extrarenal excretion in a steam bath. Additional water loss via sweat could give short term beneficial evaporative cooling to the body. But xanthines may produce dehydration under long term heated conditions, ultimately putting stress on the thermoregulatory system. During sitting rest Biren et al. (1992) found skin temperatures to increase with caffeine during heated conditions. Caffeine also increased oxygen uptake which would normally result in heat storage (Pandolf et al., 1988). Rectal temperature remained constant, most likely due to vasodilation in the skin (causing higher skin temperatures) thereby increasing heat conductance from the core to the surface of the body. Using an ephedrinecaffeine mixture on humans exposed to a cold environment for three hours, Valerand et al. (1989) found the drop in core, mean skin, and mean body temperatures were significantly less $(\underline{p}<.01)$ during the ephedrine/caffeine trial when compared with the placebo trial, but the exclusive effect of caffeine was not determined.

Two investigators found that caffeine had no effect on thermoregulation during exercise in the cold (Doubt et al., 1991; Graham et al., 1991). But Graham et al. (1991) did 
find a significant increase in rectal temperature during sub-maximal exercise in $28^{\circ} \mathrm{C}$ with ingestion of $5 \mathrm{mg}$ caffeine / kg body weight.

Falk et al. (1990) found that caffeine tended to produce greater sweat rate $(p<.07)$ and higher final rectal temperature $(p<.068)$ during treadmill running to exhaustion under normal ambient conditions. The only field study by Gordon et al. (1982) found that $5 \mathrm{ml}$ caffeine/kg body had no significant differences on rectal temperature at the completion of a two-hour run. Two out of 10 subjects reached heat stroke level core temperatures $\left(>40^{\circ} \mathrm{C}\right)$. There are several pharmacological effects of caffeine which could possibly cause shifts in temperature regulation; caffeine increases water and sodium excretion o'Neil et al. (1986) and may cause dehydration and compromise evaporative and convection cooling. Caffeine stimulates resting metabolic rate (Dullo \& Miller, 1986; Dullo et al., 1989; Jequier, 1987; Leblanc et al., 1985). If the heat generated from the higher metabolic rate is not released through either increased convection, radiation, conduction, or evaporation, heat storage (and therefore body temperature) would ultimately be increased. The stimulating effect of caffeine on the sympathetic nervous and cardiovascular systems may also play an important role in human temperature regulation (Rosenbloom 
\& Sutton, 1985).

Caffeine increases resting metabolic rate (Dullo \& Miller, 1986; Dullo et al., 1989; LeBlanc et al., 1985) and produces dose dependent temperature changes in rats (Iin et al., 1980; Scholsberg, 1983). Research using human subjects found that xanthines: (1) increase sweating in steam bath conditions (Starkenstein, 1927); (2) increase skin temperature during heat exposure (Biren et al., 1992); (3) increase rectal temperature during immersion in $28^{\circ} \mathrm{C}$ water (Graham et al., (1991); (4) have no effect on thermoregulation during cold exposure (Doubt et al., 1991; Graham et al., (1991); (5) have no thermoregulatory effect in a normal ambient or hot ambient environments during rest (Biren et al., 1992); and (6) have no thermoregulatory effect during exercise (Falk et al., 1990; Gordon et al., 1982) .

Studies on humans incorporating adequate controls in a normal environment, and when the thermoregulatory system is stressed (as during exercise), are necessary to determine the possible effect of caffeine on human temperature regulation. 


\section{CHAPTER III \\ Methods \\ Introduction}

This chapter will present information on the subjects, and the measurements and methods to be used in the present investigation.

\section{Subjects}

The experimental protocol for this study was approved by the San Jose State University Human Subjects

Institutional Review Board. Subjects were solicited verbally and through posted advertisement (Appendix C). Twelve male volunteers were tested, but data from one of the volunteers were not included due to difficulties with temperature measurements. Each subject was screened via questionnaire (Appendix A) for age, sex, medical history, family health history, addictive habits, and exercisetraining routines. Only those considered "apparently healthy" by the standards found in the American College of Sports Medicine's (ACSM) Guidelines for Exercise Testing and Prescription (4th edition, 1991) were used in this study. Since fat provides thermal resistance (Toner \& McArdle, 1988), subject's fat content was required to be below $18 \%$ fat (as measured by underwater weighing). All of subjects were non-smokers. Five of the subjects consumed 
less than $100 \mathrm{mg}$ caffeine per day; 3 subjects consumed 100-200 mg caffeine per day; and 2 subjects consumed 200$450 \mathrm{mg}$ caffeine per day.

Additionally, only active volunteers (who exercised aerobically for a minimum of 30 minutes at least three times per week) were selected, since fitness level alters caffeine's effect on resting metabolic rate (LeBlanc et al., 1985). Volunteers were informed of the procedures and the possible risks of participating in this research, and subject consent (Appendix B) was obtained before initiation of testing.

\section{Measurements and Methods}

The 11 subjects completed three testing sessions. First, in the pre-test session the subject's weight, height, body fat percentage, and maximum oxygen uptake were measured. Using a single blinded method, the subjects then performed a caffeine and a non-caffeine exercise sessions. Both exercise sessions were completed within two weeks of the pre-test. The first exercise session took place at least 2 days after the pre-test. The second exercise session took place a minimum of 2 days after the noncaffeine exercise session or a minimum of 4 days after the caffeine exercise session. 


\section{Pre-test}

Subjects were instructed not to eat, or drink 3 hours prior to testing (ACSM, 1991), and to not exercise for 12 hours before the pre-test. Data were recorded on a pre-test form (Appendix C) from measurements taken in the following order: height, weight, residual lung volume, body composition (relative fat, fat weight, and fat free weight), and maximum oxygen uptake.

Height

A stadiometer was used to measure the subjects height. The bare-footed subject stood (heels together) with his heel, buttocks, scapula, and cranium against a vertical pre-measured surface. With head held upright, arms to the side, and weight distributed evenly on both feet, the subject inhaled deeply and maintained an upright position as the technician brought the headboard to the most superior part of the subject's scalp. The subject then stepped away as the technician held the headboard in position and measured the subject's height to the nearest $0.1 \mathrm{~cm}$ (Christensen, 1990). Weight

Subjects wore only shorts as they were weighed on a calibrated Accu-Weight Scale (San Erancisco, CA). With weight evenly distributed on both feet the subject stood in the center of the platform and the technician added or 
removed weights, and then moved the slide of the scale until the beam was centered. Weight was recorded to the nearest $0.05 \mathrm{~kg}$ (Christensen, 1990).

\section{Maximal exygen Uptake}

Maximal oxygen uptake was determined using a continuous progressive exercise method on a Monark 818 cycle ergometer at a pedal cadence of 60 revolutions per minutes (rpm). The ergometer seat was adjusted to allow the subject near full leg extension, and the handle bars was adjusted to a comfortable level. Before the test began the subject was informed about the testing procedure and given an opportunity to ask questions. During this pretest a 10-second resting electrocardiogram strip was obtained. Throughout the test, respiratory parameters and heart rate were monitored continuously.

After a 5 minute warm-up at a power output of 180 kilopond meters per minute $(\mathrm{kpm} / \mathrm{min})$, the resistance was increased by $180 \mathrm{kpm} / \mathrm{min}$ each minute until the subject was unable to maintain the $60 \mathrm{rpm}$ speed. The test would have been terminated if: (1) the subject did not elect to or could not continue; (2) the equipment failed; (3) the ECG showed abnormalities; and/or (4) signs of distress were indicated by loss of coordination (ACSM, 1991). Upon completion of the maximal test the subject was given a three to five minute exercise cool-down period in which the 
heart rate declined to below 120 beats per minute. Before removing the electrodes, a final ECG strip was obtained.

The subject's heart rate was measured using a standard V5 electrode lead placement. Electrodes were connected to a type 410 physiological monitor (Tektronix Incorporated; Portland, OR) interfaced to a model 462 strip chart recorder (Thornton Associates Incorporated; Waltham, MA). An electrocardiogram (ECG) was printed (paper speed of 25 $\mathrm{mm}$ per minute) for the last 10 seconds of each minute during the test.

A headpiece attached to a Hans-Rudolph (Kansas City, MO) respiratory valve and mouthpiece was fitted to the subject. A nose clip was also attached to force breathing through the mouth. Inhaled air entered through a Parkinson-Cowan CD-4 dry test meter (New York, NY) and through the respiratory valve. A potentiometer, interfaced with an Apple II computer, recorded the volume of inspired air. Expired air passed through the Hans-Rudolph valve into a mixing chamber, then through a wilmore-Costill spinner Valve system (WCVS) into two gas analyzers. The oxygen $\left(\mathrm{FeO}_{2}\right)$ and carbon dioxide $\left(\mathrm{FeCO}_{2}\right)$ concentrations of the expired air were measured with a Beckman LB-2 Medical Gas analyzer (Fullerton, $C A$ ) and an Applied Electrochemistry 5$3 A$ analyzer (Sunnyvale, CA). Both analyzers were connected to an Apple II computer. To insure accurate gas analysis, 
the gas analyzers were calibrated before and periodically during each test by the same technician. Data from inspired air and expired $\mathrm{FeO}_{2}$ and $\mathrm{FeCO}_{2}$ concentrations were calculated from one minute samples. Expired ventilation $\left(V_{E}\right)$ was calculated from the inspired ventilation rate $\left(V_{I}\right)$, oxygen uptake $\left(\mathrm{VO}_{2}\right)$, and carbon-dioxide production $\left(\mathrm{VCO}_{2}\right)$; respiratory exchange ration $\left(\mathrm{R}_{\mathrm{E}}\right)$ was calculated from $\mathrm{VCO}_{2}$ and $\mathrm{VO}_{2}$.

Body Composition

Body composition was determined by underwater weighing with correction for residual lung volume. Using the oxygen dilution method, residual lung volume was determined by averaging the two closest measurements (provided the measurements were within $2 \%$ of each other) collected from a model 505 Nitrayzer nitrogen gas meter (Med Science, St. Louis, MO). The same technician calibrated the Nitrayzer prior to each test.

To measure weight underwater (using a water filled tank), the subjects wore a weighted belt and sat in a webbed sling suspended from a Chatilion scale (New York, NY). Six to 10 trials were given where the subject exhaled as much air as possible when completely immersed. The average of three trials (that were within $\pm 0.05 \mathrm{~kg}$ ) were used for the underwater weight (Cisar et al., 1987). Body composition was calculated using the equation developed by 
Brozek, Grande, Anderson, and Keys (1963).

Caffeine/Non-Caffeine Sessions

The two exercise sessions were performed in an identical manner except the subjects were given either a non-caffeinated or a caffeinated drink. To control the possible effects of circadian rhythms on body temperature, both caffeine/non-caffeine sessions were conducted in the morning, at approximately the same time of the day (Stephenson \& Kolka, 1988). Subjects wore brief shorts, shoes, and ankle socks. Back-up data were recorded on separate data collection sheets (Appendix F). The following paragraphs will present information on: preexercise test requirements; caffeine administration; environmental conditions; pre- and post-test weights; resting rectal temperature, mean skin temperatures, heart rate and oxygen uptake; exercise procedures; and exercise rectal temperature, mean skin temperatures, heart rate and oxygen uptake. Body surface area, average skin temperature, mean body temperature, respiratory water loss, sweat loss, and skin heat conductance formulas are included within the temperature sections.

Pre-Exercise Session Requirements

To eliminate any previously developed caffeine tolerance, before both exercise sessions the subjects were given a list of caffeine containing substances (Appendix D) 
and asked not to eat or drink any caffeine containing substances for at least four days prior to their tests (Fisher, McMurray, Berry, Mar \& Eorsythe, 1986). To help normalize their hydration level, the subjects were asked to refrain from alcohol 24 hours prior to testing, and to not eat or drink eight hours prior to testing, and to abstain from strenuous exercise 24 hours before each exercise test. Caffeine Administration

Both exercise tests were performed in an identical manner except subjects were given either a control mixture or a caffeine mixture. The control mixture contained Sugar Free Crystal Iight (Kraft General Foods, Inc., White Plains, NY) dissolved in $237 \mathrm{ml}$ ( 8 ounces) of water $\left(37^{\circ} \mathrm{C}\right.$ ). The caffeine test used the same mixture with caffeine (Chemicals for Research and Industry, Martinez, CA) added at a dosage equivalent to $10 \mathrm{mg} / \mathrm{kg}$ body weight. To control psychosomatic effects related to learning or expectation the subjects were not told which session they were attempting. Several subjects did comment on the bitter taste of the caffeine drink. Five of the 11 subjects completed the caffeine session first. Environmental conditions

The environmental conditions, including dry bulb and wet bulb temperatures and barometric pressure, were recorded prior to and after the caffeine/non-caffeine 
sessions. Rectal temperature levels during exercise are independent of ambient air temperatures between 5 and $30^{\circ} \mathrm{C}$ (41 and $86^{\circ} \mathrm{F}$ ) (Gonzalez, Berglund \& Gagge, 1978; Lind, 1963; Nielsen, 1970; Stolwijk, Saltin \& Gagge, 1968). Ambient air temperatures during this study $20.72 \pm 0.80^{\circ} \mathrm{C}$. A fan was turned on in front of the subjects during the exercise phase to enhance sweat evaporation and to keep sweat from dripping. Wind speed was measured via a hot wire anemometer and recorded three times during each session.

Pre and Post Session Weight

The same technician weighed the nude subject before he drank either mixture. The same equipment and procedures were used as in the pre-test session. The weight of the drink was added to the pre-exercise body weight. Then, immediately after the cool-down period, all equipment was removed from the subject and the remaining moisture wiped off before the final weight was measured and recorded. Measurements Taken at Rest

Equipment required for data collection were attached to the subject after he had been initially weighed. Baseline measurements of heart rate were recorded prior to liquid ingestion. Electrode and thermistor placement are shown in Figures 1 and 2. The experimental set up is shown in Figure 3. Drinks were ingested within one minute, when 
session time started. Rectal temperature and skin temperatures were recorded every minute, heart rate, $\mathrm{VO}_{2}$, and $\mathrm{VCO}_{2}$ were recorded the $1^{\text {st }}, 2^{\text {nd }}$ and $3^{\text {rd }}$ minutes, and every $8^{\text {th }}, 9^{\text {th }}$, and $10^{\text {th }}$ minute of each 10 minute cycle thereafter.

\section{Rectal Temperature}

After being weighed, the subject inserted a rectal probe (Yellow Springs Instrument Company; Yellow Springs, $\mathrm{OH}) 16 \mathrm{~cm}$ as indicated by a predetermined mark on the probe. The rectal probe was interfaced with a squirrel Meter-Logger (Science Electronics Inc., Miamisburg, $\mathrm{OH}$ ). Data collected on the squirrel were downloaded and processed on a IBM compatible Leading Edge model "D" computer (Leading Edge Hardware Pro., Inc., Canton, MA). Rectal temperature $\left(T_{\text {re }}\right)$ was recorded to the nearest $0.01^{\circ} \mathrm{C}$ every minute. 
Thermistor

Placement

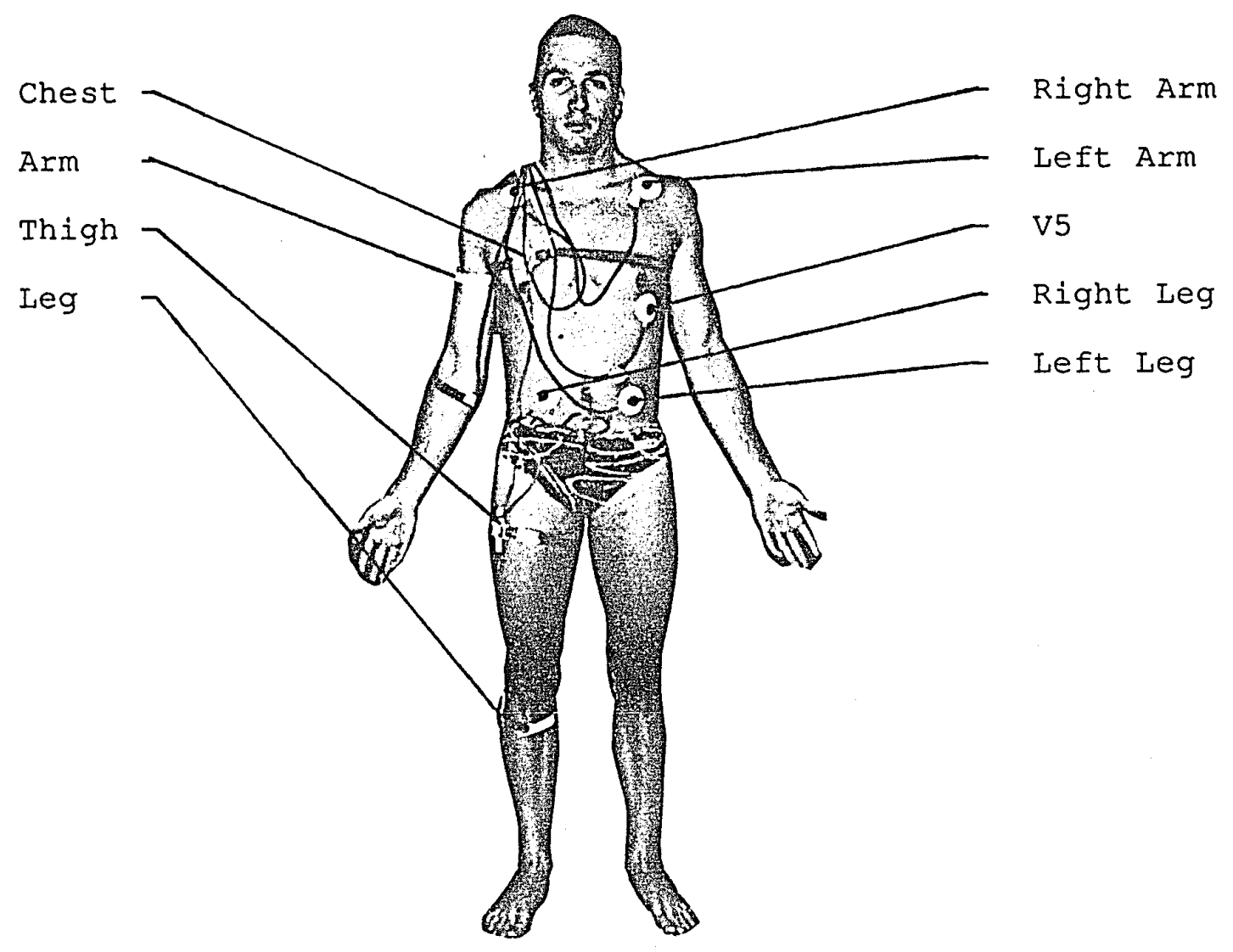

Electrode

Placement

FIGURE 1

Electrede and Thermistor Placement 


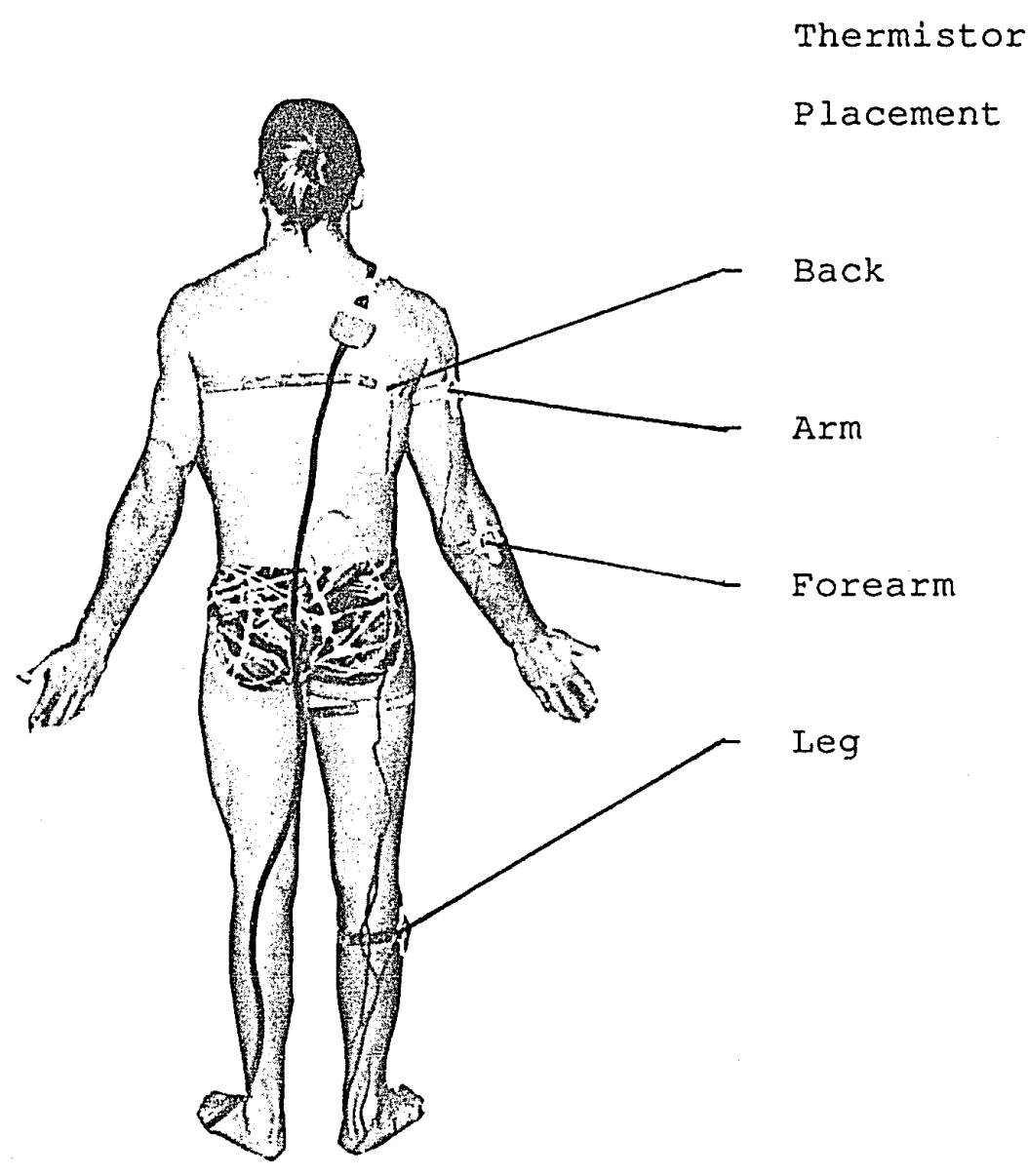

FIGURE 2

Thermistor Placement 


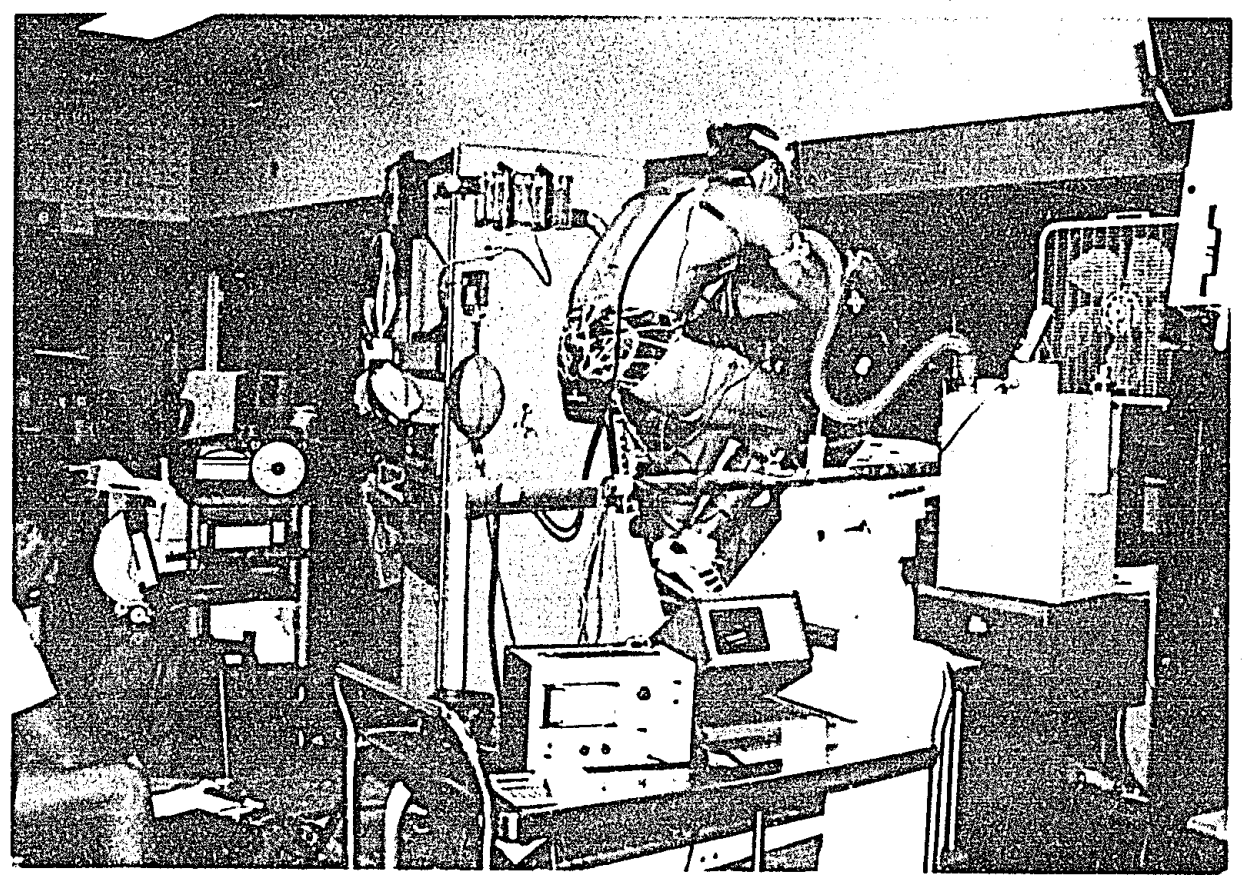

FIGURE 3

Experimental set Up 
Skin surface Temperatures

Thermistors were attached to the skin with a prototype model of the YSI model PHO9 probe holders which allowed for free air circulation around them. Thermistors were interfaced with a Squirrel Meter - Logger (Science Electronics Inc., Miamisburg, $\mathrm{OH})$. Data collected on the Squirrel were down-loaded and processed on a IBM compatible Leading Edge model "D" computer (Leading Edge Hardware Pro., Inc., Canton, MA). Attachment sites for the thermistors were on the right side in the following positions: (1) arm - over the deltoid insertion on the humerus; (2) forearm - over the belly of the extensor carpi radialis longus; (3) chest - $3 \mathrm{~cm}$ over nipple; (4) back directly posterior to the chest probe; (5) thigh - over the middle of the vastus lateralis; and (6) leg - on the lateral side and over the belly of the gastrocnemius muscle (J. E. Greenleaf, personal communication, February 27, 1991). Mean skin temperature $\left(\mathrm{T}_{s k}\right)$ was calculated as: 0.06 $(\mathrm{arm})+0.13$ (forearm) +0.19 (chest) +0.20 (back) +0.21 (thigh) +0.21 (leg temperature) using the formula from Greenleaf and Castle (1972).

\section{oxygen Uptake}

oxygen uptake, carbon-dioxide production, expired ventilation, and respiratory exchange ratio were collected using the same technique and equipment as during the 
maximal oxygen uptake rate. Oxygen uptake, carbon-dioxide production, expired ventilation, and respiratory exchange ratio were recorded the first, second and third minutes, and the eighth, ninth, and tenth minutes of each 10-minute cycle thereafter.

Body Surface Area

Body surface area was calculated with the DuBois formula cited by Greenleaf and Reese (1980) where body surface area ( $\mathrm{SA}$ ) in $\mathrm{m}^{2}$ was:

$71.84[(w t) 0.425 \times(h t) 0.725)] \because 10^{-4}$

Mean Body Temperature

Mean body temperature was calculated from Greenleaf and Reese (1980) where mean body temperature $\left(\mathrm{T}_{\mathrm{mb}}\right)$ in ${ }^{\circ} \mathrm{C}$ was:

$\mathrm{T}_{\mathrm{mb}}=0.8\left(\mathrm{~T}_{\mathrm{re}}\right)+0.2\left(\mathrm{~T}_{\mathrm{sk}}\right)$

\section{Iotal Water Iuss}

Total water loss was calculated with an equation from Ekblom, Greenleaf, Greenleaf, and Hermansen (1971), where total water loss in $\mathrm{g} / \mathrm{m}^{2} / \mathrm{hr}$ was:

$\mathrm{H}_{2} \mathrm{O}_{\text {tot }}=\{($ total wt loss $/ \mathrm{SA})$ 


$$
\left.-\left[118.614\left(\mathrm{~V}_{\mathrm{CO} 2}\right)-85.742\left(\mathrm{VO}_{2}\right)\right]\right] \times \mathrm{L} / \mathrm{m}^{2}
$$

Respiratory water loss

Respiratory water loss was calculated from an equation by Ekblom et al. (1971). Respiratory water loss in $\mathrm{g} / \mathrm{m}^{2} / \mathrm{hr}$ was:

$\mathrm{H}_{2} \mathrm{O}_{\text {res }}=$ VE $\mathrm{BTPS}\left[\left(\mathrm{H}_{2} \mathrm{O}_{\mathrm{do}}-\mathrm{H}_{2} \mathrm{O}_{\text {dar }}\right) \times \mathrm{O}_{\mathrm{a}}\right] \times 60 / \mathrm{m}^{2}$

Where:

$\mathrm{H}_{2} \mathrm{O}_{\mathrm{do}}=$ water density at oral temperature (the mean oral temperature was determined using measurements taken prior to liquid consumption, and just after exercise completion). $\mathrm{H}_{2} \mathrm{O}_{\text {dar }}=$ water density at ambient room temperature. $0_{a}=$ relative humidity at ambient room temperature.

Sweat loss

Sweat loss was calculated using an equation from

Ekblom et al. (1971). Sweat loss in $\mathrm{g} / \mathrm{m}^{2} / \mathrm{hr}$ was:

Sweat Loss $=\left(\mathrm{H}_{2} \mathrm{O}_{\mathrm{t}}-\mathrm{H}_{2} \mathrm{O}_{\mathrm{rl}}\right)-\mathrm{H}_{2} \mathrm{O}_{\mathrm{il}}$

Where:

$\mathrm{H}_{2} \mathrm{O}_{\mathrm{tl}}=$ total water loss (weight lost in grams).

$\mathrm{H}_{2} \mathrm{O}_{\mathrm{rl}}=$ respiratory water loss.

$\mathrm{H}_{2} \mathrm{O}_{\mathrm{il}}=$ insensible water lose (equivalent to $18 \mathrm{~g} / \mathrm{m}^{2} / \mathrm{hr}$ ). 


\section{Skin Heat Conductance}

Mean skin heat conductance (Hsk) was calculated from the conductance equation of Greenleaf and Reese (1980) where mean skin heat conductance ( $\mathrm{Hsk}$ ) in $\mathrm{kcal} / \mathrm{m}^{2} / \mathrm{h} /{ }^{\circ} \mathrm{C}$ was:

$$
\text { Hsk }=\frac{M_{\text {gross }}-E_{\text {res }}-C_{\text {res }}-W-(+S)}{\text { SA }\left(X T_{\text {re60-70 }}-X_{\text {Sk60-70 }}\right)}
$$

Where:

$$
\begin{aligned}
& \text { Mgross = total heat production from oxygen uptake } \\
& (\mathrm{kcal} / \mathrm{h}) \\
& \text { Eres = evaporative heat loss from the respiratory } \\
& \text { tract }(\mathrm{kcal} / \mathrm{h}) \\
& =0.58 \text { (respiratory water loss) } \\
& \text { Cres = conductive and convective heat loss from the } \\
& \text { respiratory tract }(\mathrm{kcal} / \mathrm{h}) \text {, assumed to be zero } \\
& \mathrm{W} \quad \text { heat loss due to external work ( } \mathrm{kcal} / \mathrm{h}) \\
& =0.86 \mathrm{x} \text { (work load in watts) } \\
& +\mathrm{S}=\text { change in body heat storage }(\mathrm{kcal} / \mathrm{h}) \\
& =0.83 \times \text { wt }\left[0.8\left(\operatorname{Tre}_{\text {re }} 70-60\right)+0.2\left(\mathrm{Tsk}_{\mathrm{sk}} 70-60\right)\right] \times 6 \\
& \text { weight (wt) in kilograms } \\
& \mathrm{SA}=\text { body surface area }\left(\mathrm{m}^{2}\right) \\
& =71.84 \times\left[w t^{(0.425)} \times h^{(0.725)}\right] \times 10^{-4} \\
& \text { height (ht) in centimeters } \\
& \text { Tre60 = rectal temperature after } 60 \text { minutes }
\end{aligned}
$$


$\mathrm{XT}_{\text {re }} 60-70=$ mean of $\mathrm{T}_{\text {re }}$ measured at 60,65 , and 70 minutes Tre 70-60 = the difference between Tre 70 and Tre 60 Heart Rate

The subject's heart rate was measured using a standard V5 electrode lead placement connected to a model 410 physiological monitor (Tektronix Incorporated, Portland, OR) interfaced with a type 462 strip chart recorder (Thornton Associates Incorporated; Waltham, MA). An electrocardiogram (ECG) was printed (using a paper speed of $25 \mathrm{~mm}$ per minute) the last 10 seconds of the 1st, $2^{\text {nd }}$, and $3^{\text {rd }}$ minutes, and the last 10 seconds of every $8^{\text {th }}, 9^{\text {th }}$, and $10^{\text {th }}$ minute of each 10 minute cycle thereafter for the duration of the test.

\section{Exercise Procedures}

After a 30 minute rest period the subject seated on the ergometer initiated cycling exercise and continued for 70 minutes. Caffeine blood level should have peaked during the exercise period since caffeine concentrations peak 30 to 60 minutes after ingestion (Jackobson \& Kulling, 1989). Since the rise rectal temperature is dependent on the relative exercise load (Saltin \& Hermanssen, 1966), the subject cycled using the same constant exercise load equivalent to approximately $65 \%$ of his previously determined $\mathrm{VO}_{2} \max$. The exercise load was determined from 
the following equation (Lang, Latin, Berg \& Mellion, 1992) where exercise load in in $\mathrm{kgm} / \mathrm{min}$ is:

Load $=\left\{\mathrm{VO}_{2}(\mathrm{ml} / \mathrm{min})-[(3.5 \mathrm{ml} / \mathrm{kg} / \mathrm{min} \times \mathrm{kg}\right.$ body weight $)$ $+260 \mathrm{ml} / \mathrm{min}]\} / 1.9 \mathrm{ml} / \mathrm{min}$.

A fan was turned on at the start of exercise to increase convective cooling and enhance evaporation sweat loss. To reduce sweat loss via dripping and enhance evaporative heat loss, sweat was wiped to drier areas of the body. Verbal encouragement was given throughout the exercise session.

The test protocol would be terminated if: (1) the subject did not want to (or could not) continue; (2) the equipment failed; (3) the ECG showed abnormalities indicating signs of distress; (4) signs of distress were indicated by loss of coordination (ACSM, 1991); or (5) if rectal temperature reached $40^{\circ} \mathrm{C}$. Upon completion of the caffeine/non-caffeine sessions, the subject was given a 3 to 5 minute exercise cool-down period in which the heart rate declined to below 120 beats per minute. Before removing the electrodes a final ECG strip was obtained. Rhysiological Parameters Monitored During Exercise

Exercise rectal temperature, mean skin temperatures, heart rate, $\mathrm{VO}_{2}$, and $\mathrm{CO}_{2}$ continued to be recorded during 


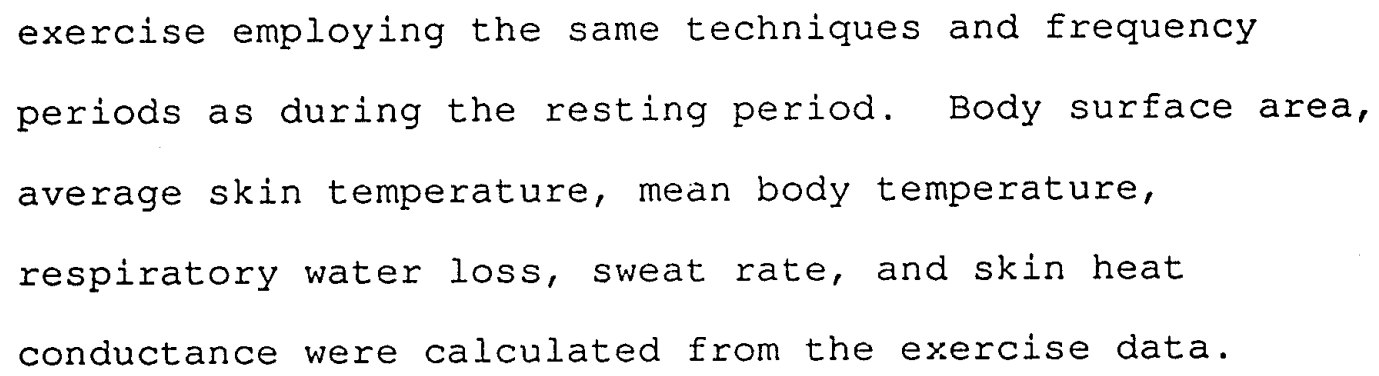


CHAPTER IV

DATA ANALYSIS

\section{Introduction}

This chapter will present information pertaining to: the level of significance, analysis of data, summary of findings, discussion of findings, conclusions, weaknesses, and recommendations for future research.

\section{Level of Significance}

A probability level (p) of .05 or less was selected as the level of statistical significance for all data analysis.

\section{Analysis of data}

Although 12 healtny men were tested, data from only 11 subjects were analyzed due to difficulties in collecting accurate temperature data for one subject. Mean, standard deviation, standard error of the mean, variance, standard error of the skew, range, minimum, maximum and sum were calculated for each variable to examine the descriptive nature of the data. Repeated measures two-way analysis of covariance were used to control for possible differences between the caffeine and control sessions at the average $9^{\text {th }}$ minute. The repeated measures two-way analysis of 
covariances was used to determine changes in the variables measured across time and to compare differences of effects of the two test treatments (control or caffeine) on the dependent variables. If significant interaction was present between the caffeine and control sessions, data were plotted to observe where the interaction occurred. Summary tables for each of the two-way analysis of covariance tests are presented in Appendix G. Repeated measures one-way analysis of variances (ANOVA) and Tukey post-hoc tests were used to determine if significant main effects were found across time in the caffeine or control sessions. Dependent $t$-tests were used to determine if significant differences exited between the two sessions in total weight loss, weight loss in grams per hour, total water loss, and total sweat loss.

Table 1 summarizes anthropometric and physiological data. Table 2 summarizes environmental conditions present during testing. Weight and sweat loss data collected during the caffeine and control sessions are summarized in Table 3, and physiological data collected during the caffeine and control sessions are summarized in Table 4. 
Table 1

Anthropometric and Physiological Data

\begin{tabular}{lrrrrrrr}
\hline Age & $\begin{array}{l}\text { Surface } \\
\text { Area } \\
\left(\mathrm{m}^{2}\right)\end{array}$ & $\begin{array}{l}\text { Height } \\
(\mathrm{cm})\end{array}$ & Fat $\frac{\text { Exercise }}{\mathrm{Load}}$ & $\begin{array}{l}\mathrm{VO}_{2} \mathrm{max} \\
\mathrm{L} / \mathrm{min}\end{array}$ & $\begin{array}{c}\mathrm{VO}_{2} \mathrm{max} \\
\mathrm{mL} / \mathrm{kg} / \mathrm{min}\end{array}$ \\
\hline Mean 29.18 & 1.961 & 180.14 & 12.3 & 1088.18 & 3.73 & 48.7 \\
$\pm \mathrm{SD}$ & 6.21 & .116 & 4.43 & 3.7 & 153.02 & .46 & 6.2 \\
\hline
\end{tabular}

Table 2

Ambient Environmental Data

\begin{tabular}{lrrrr}
\hline & $\begin{array}{l}\text { Baro. } \\
\text { Press. }\end{array}$ & $\begin{array}{l}\text { Dry Bulb } \\
\text { Temp. }\end{array}$ & Humidity & $\begin{array}{l}\text { Wind } \\
\mathrm{m} / \mathrm{min}\end{array}$ \\
\hline Mean & 760 & 20.72 & 64.2 & 156 \\
\pm SD & 1 & .80 & 4.0 & 4 \\
\hline
\end{tabular}

Table 3

Weight and sweat loss Data During Caffeine and control Test

\begin{tabular}{lcccc}
\hline & Pre-wt & Post-wt & wt loss & $\begin{array}{l}\text { Sweat } \\
\text { loss } \\
(\mathrm{g} / \mathrm{hr})\end{array}$ \\
\hline $\begin{array}{l}\text { Caffeine Session } \\
\text { Mean }\end{array}$ & 76.76 & 75.69 & 1,072 & 378 \\
\pm SE & 2.53 & 2.50 & 84 & 36 \\
$\begin{array}{l}\text { Control Session } \\
\text { Mean }\end{array}$ & 76.85 & 75.79 & 1,062 & 393 \\
SE & 2.4 & 2.36 & 86 & 35 \\
\hline
\end{tabular}


Table 4

Rhysiological Data During Caffeine and Control Test

\begin{tabular}{|c|c|c|c|c|c|}
\hline & $\begin{array}{l}\text { Exercise } \\
\mathrm{VO}_{2} \\
\mathrm{~L} / \mathrm{min}\end{array}$ & $\begin{array}{l}\text { Exercise } \\
\frac{2}{6} \text { of } \\
\mathrm{VO}_{2} \max \end{array}$ & $\begin{array}{l}\text { Resting } \\
\mathrm{VO}_{2} \\
\mathrm{~L} / \mathrm{m}\end{array}$ & $\begin{array}{l}\text { Exercise } \\
\text { Heart } \\
\text { Rate }\end{array}$ & $\begin{array}{l}\text { Resting } \\
\text { Heart } \\
\text { Rate }\end{array}$ \\
\hline $\begin{array}{c}\text { Caffeine } \\
\text { Mean }\end{array}$ & $\begin{array}{l}\text { Session } \\
2.55\end{array}$ & 68.7 & .35 & 145 & 61 \\
\hline $\pm S E$ & .09 & 1.7 & .02 & 5 & 4 \\
\hline $\begin{array}{l}\text { Control } \\
\text { Mean }\end{array}$ & $\begin{array}{l}\text { Session } \\
2.50\end{array}$ & 67.2 & .34 & 145 & 64 \\
\hline $\pm S E$ & .09 & 2.0 & .01 & 7 & 4 \\
\hline
\end{tabular}

There were no significant differences between the caffeine and control sessions in total weight loss $(\underline{p}<.791)$, weight loss in grams per hour $(\underline{p}<.788)$, total water loss $(p<.465)$, or total sweat loss $(\mathfrak{R}<.465)$.

Means and standard errors for oxygen uptake during the caffeine and control sessions are presented in Figure 4. Mean oxygen uptake for the $2^{\text {nd }}$ minute was the average of minutes one, two, and three. There were no significant differences between sessions (p<.16), significant differences across time $(p<.001)$ and significant interaction $(\underline{p}<.032)$ between caffeine and control sessions for oxygen uptake. Resting oxygen uptake was significantly lower than exercise oxygen uptake $(\underline{p}<.05)$. Interaction where oxygen uptake for both sessions was very 
similar during rest and the first 10 minutes of exercise; then the caffeine curve rises slightly above the control session and remains higher until minute 100 where the control session rises slightly to become relatively equal to the caffeine session (Figure 4).

Means and standard errors of the mean for heart rate during the caffeine and control sessions are presented in Figure 5. There were no significant differences between sessions $(p<.458)$, significant differences across time $(p<.001)$, or significant interaction $(p<.030)$ between caffeine and control sessions for heart rate. Resting heart rates were significantly lower ( $p<.05)$ than exercise heart rates. Mean heart rate at minute 40 was also significantly lower than mean heart rate at minute 100 . Interaction occurred where the caffeine session heart rates were below the control session heart rates up until minute 50 (Figure 5). At minutes 50,60 and 70 both sessions have very similar heart rates, for minutes 80 and 90 the caffeine sessions have slightly greater non-significant heart rates, and at minute 100 both sessions are once again similar.

Means and standard errors of the mean for rectal temperature are presented in Figure 6. The differences between the caffeine and control rectal temperatures are presented in Figure 7. There were no significant 


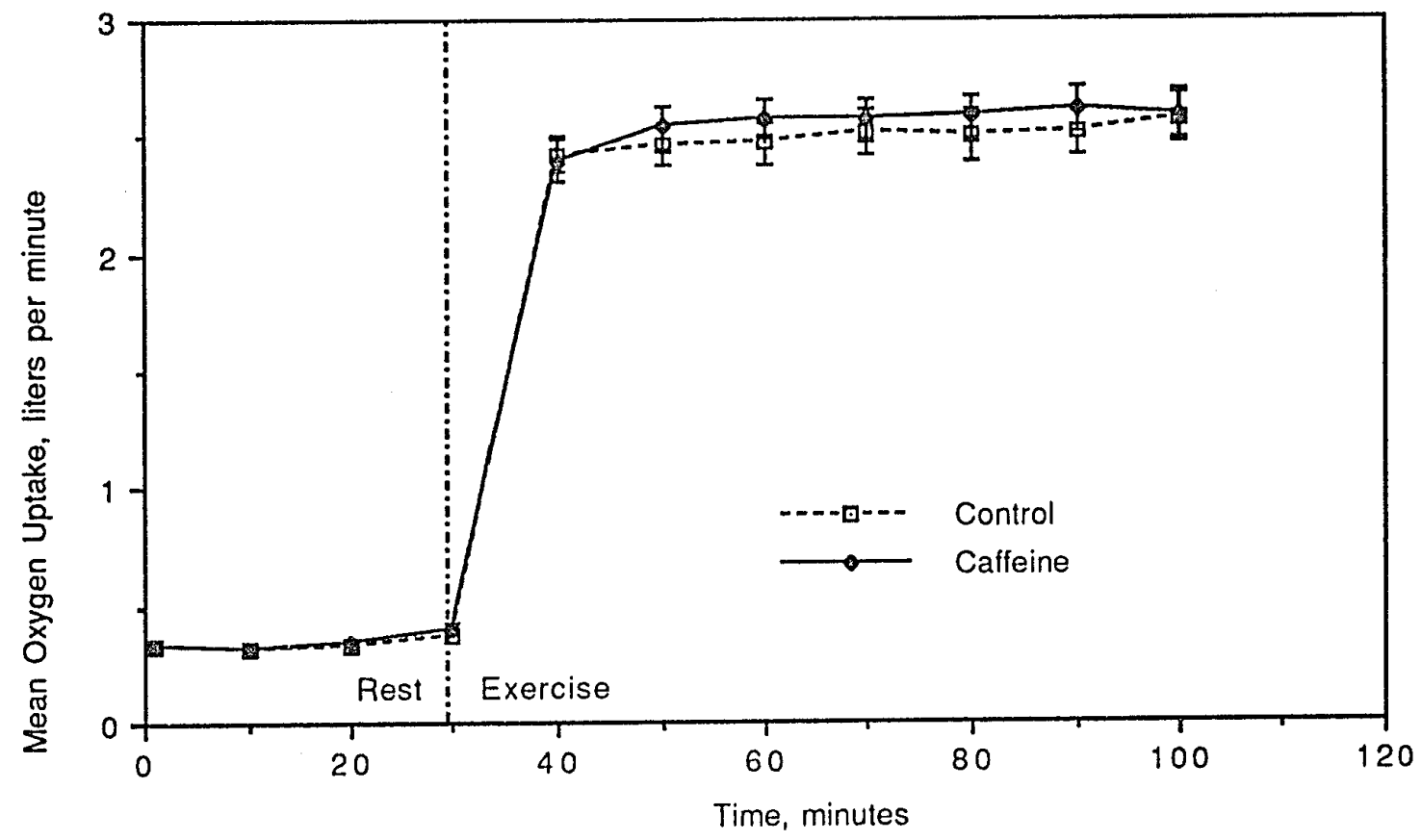

Figure 4. Oxygen Uptake ( \pm SE)

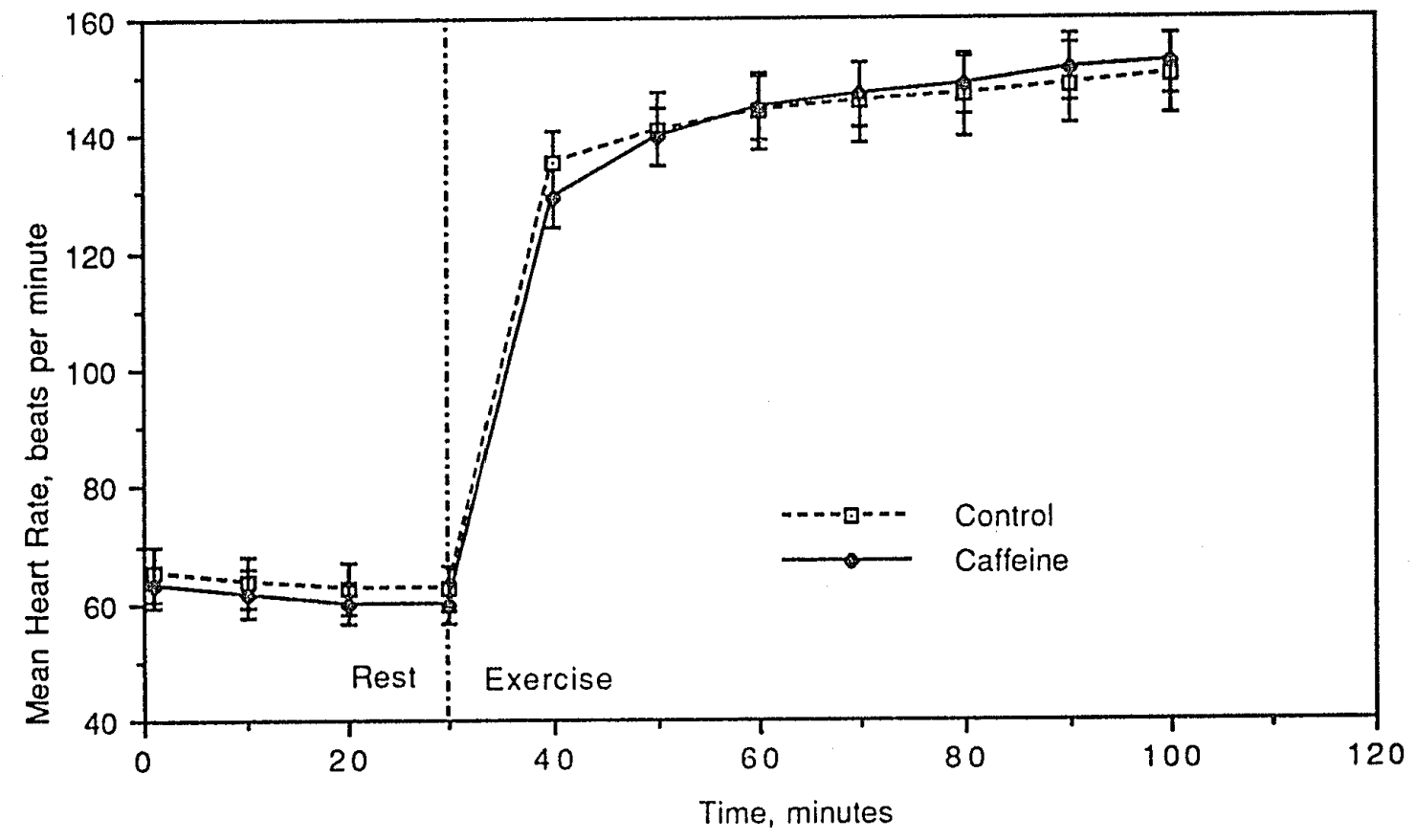

Figure 5. Mean Heart Rate $( \pm$ SE) 


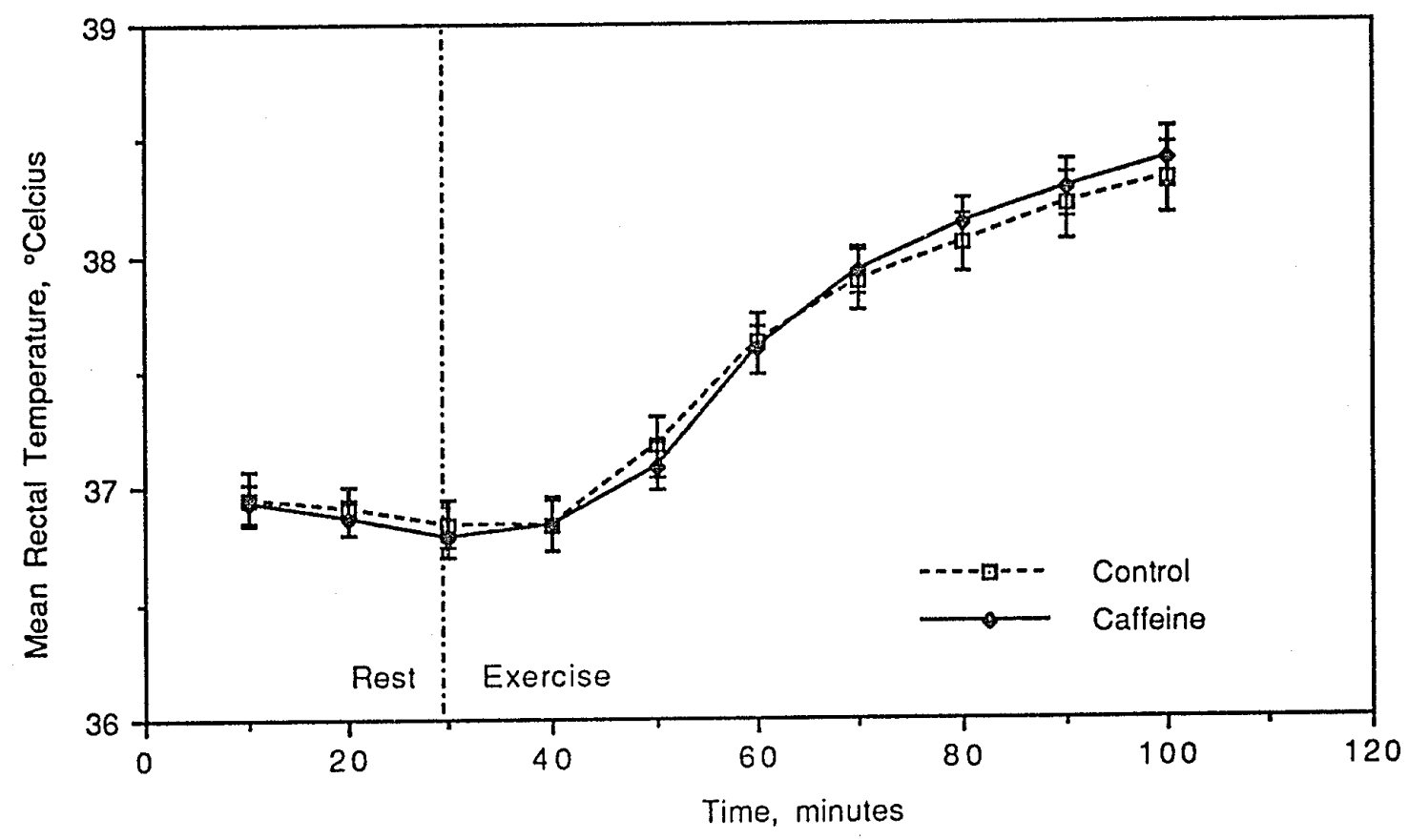

Figure 6. Mean Rectal Temperature ( \pm SE)

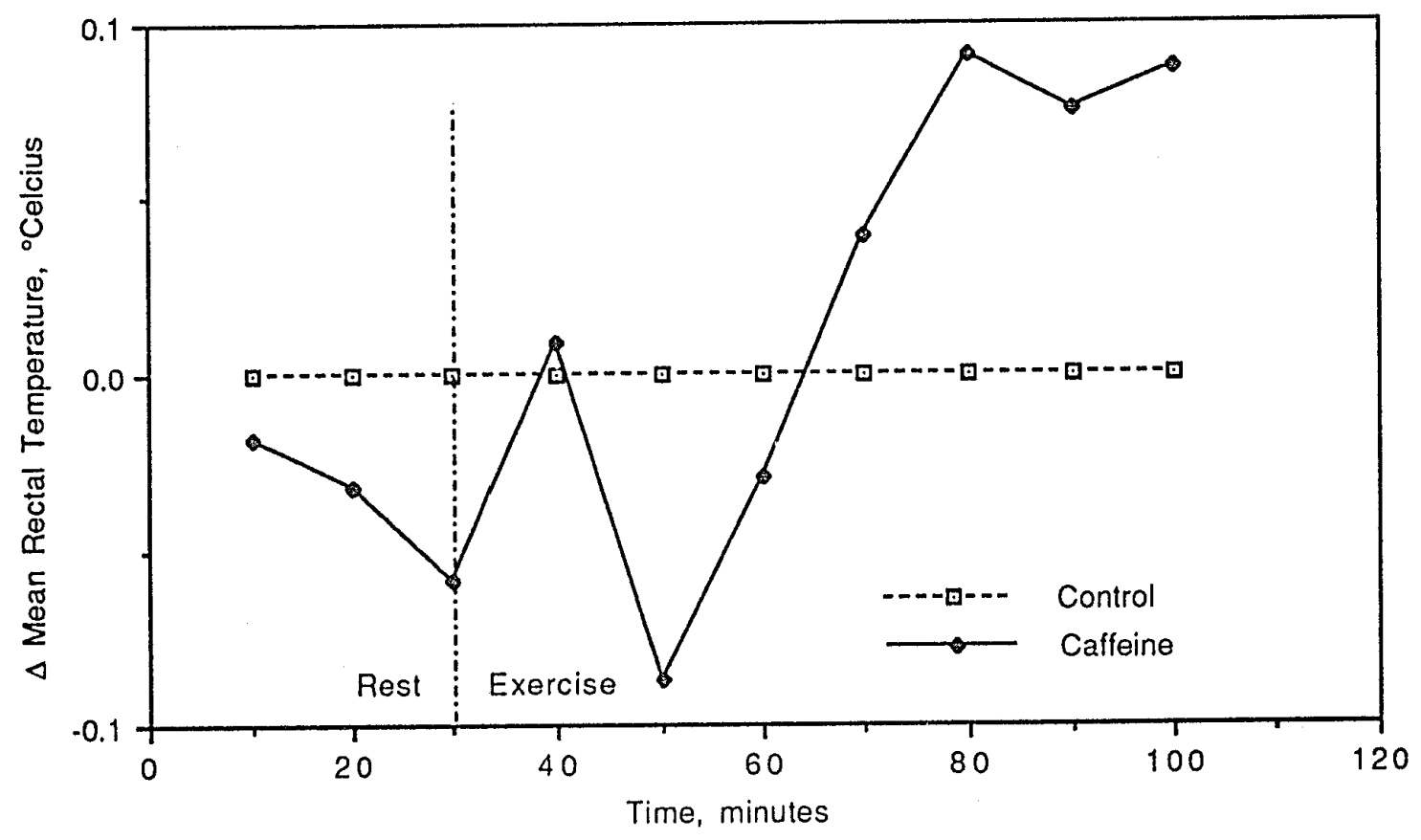

Figure 7. Mean Rectal Temperature Differences 
differences between sessions $(p<.677)$, significant differences across time $(p<.001)$, or non-significant interaction $(\underline{p}<.068)$ between caffeine and control sessions for rectal temperature. Exercise rectal temperature to be significantly higher than resting rectal temperature. Rectal temperature was significantly lower during minutes 40 and 50 than minutes 60 through 100, and rectal temperature at minute 60 was significantly lower than minutes 70 through 100 .

Means and standard errors of the mean for skin temperature are presented in Eigure 8 . Differences in mean skin temperatures for the caffeine and control sessions are presented in Eigure 9. There were no significant differences between sessions ( $p<.547)$, non-significant differences across time (ㅁ․069), or a non-significant interaction $(p<.886)$ between caffeine and control sessions for mean skin temperatures.

Figure 10 presents means and standard errors of the mean for skin heat conductance. There were no significant differences between sessions $(\underline{p}<.232)$, significant differences across time $(\underline{p}<.001)$, or a non-significant

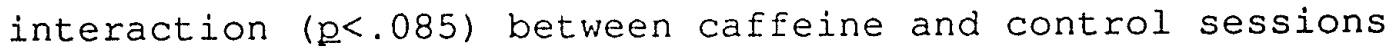
for skin heat conductance. Exercise skin heat conductance was significantly higher than resting skin heat conductance. During exercise, skin heat conductance at 


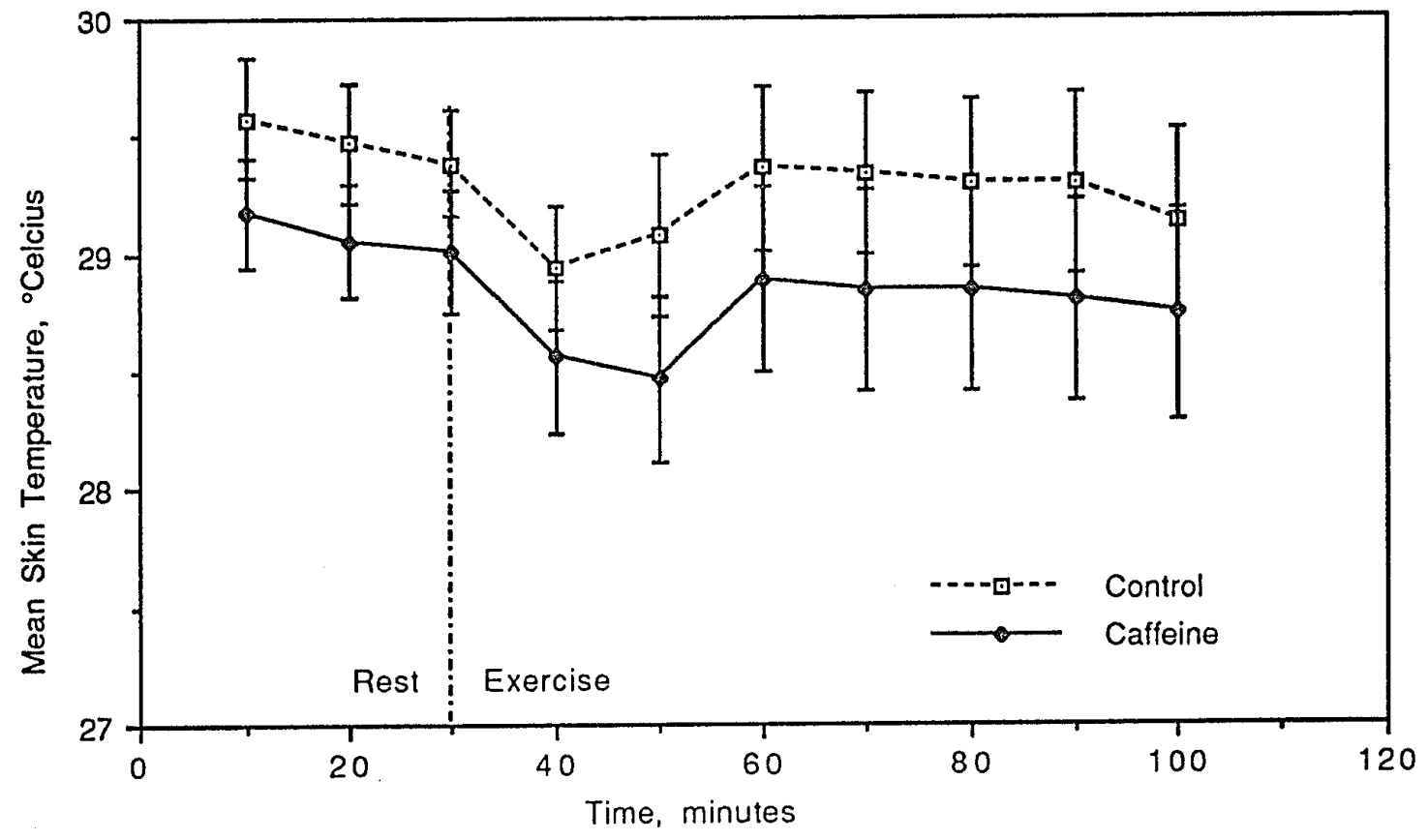

Figure 8. Mean Skin Temperature $( \pm S E)$

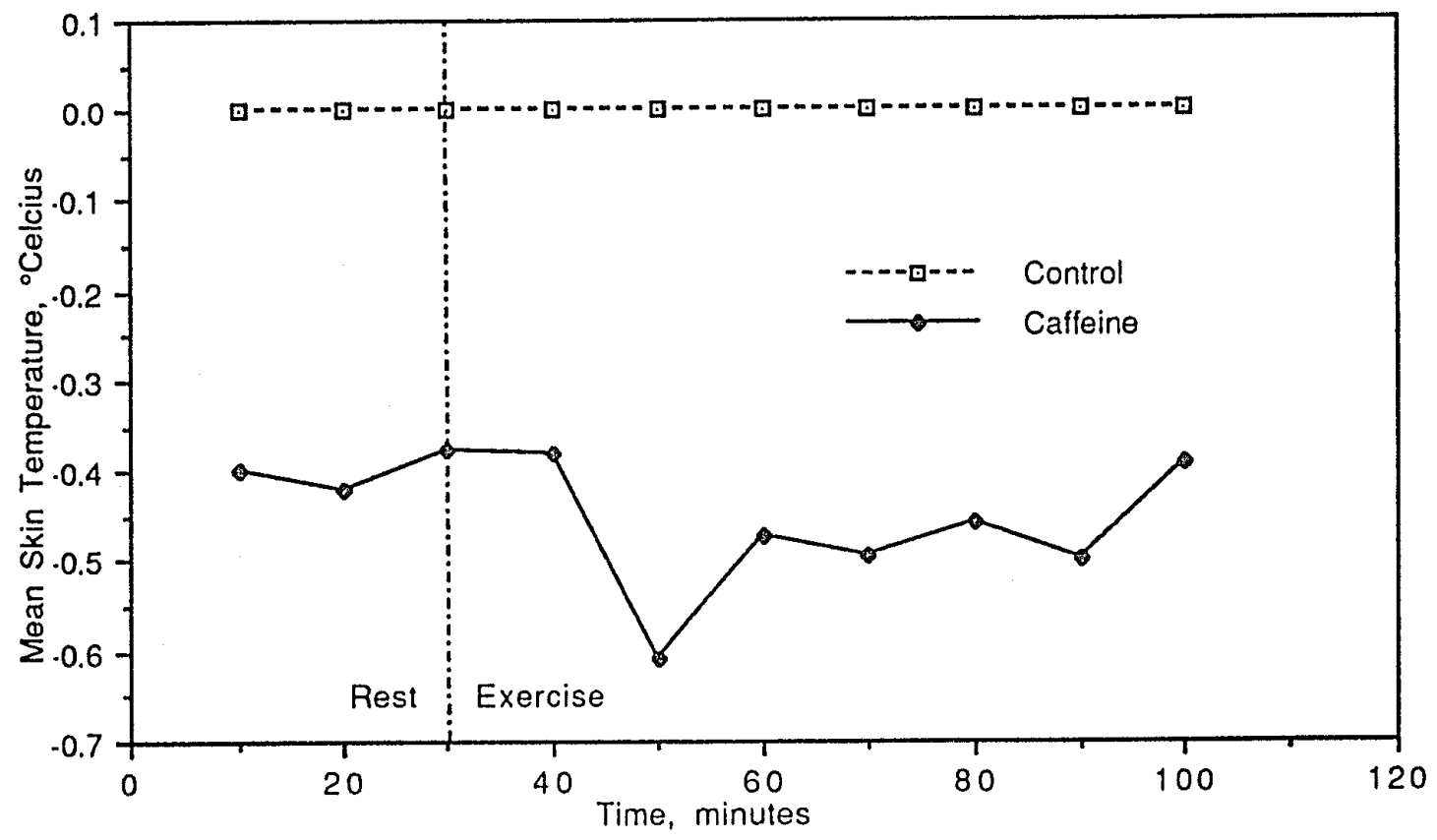

Figure 9. Mean Skin Temperature Differences ( \pm SE) 


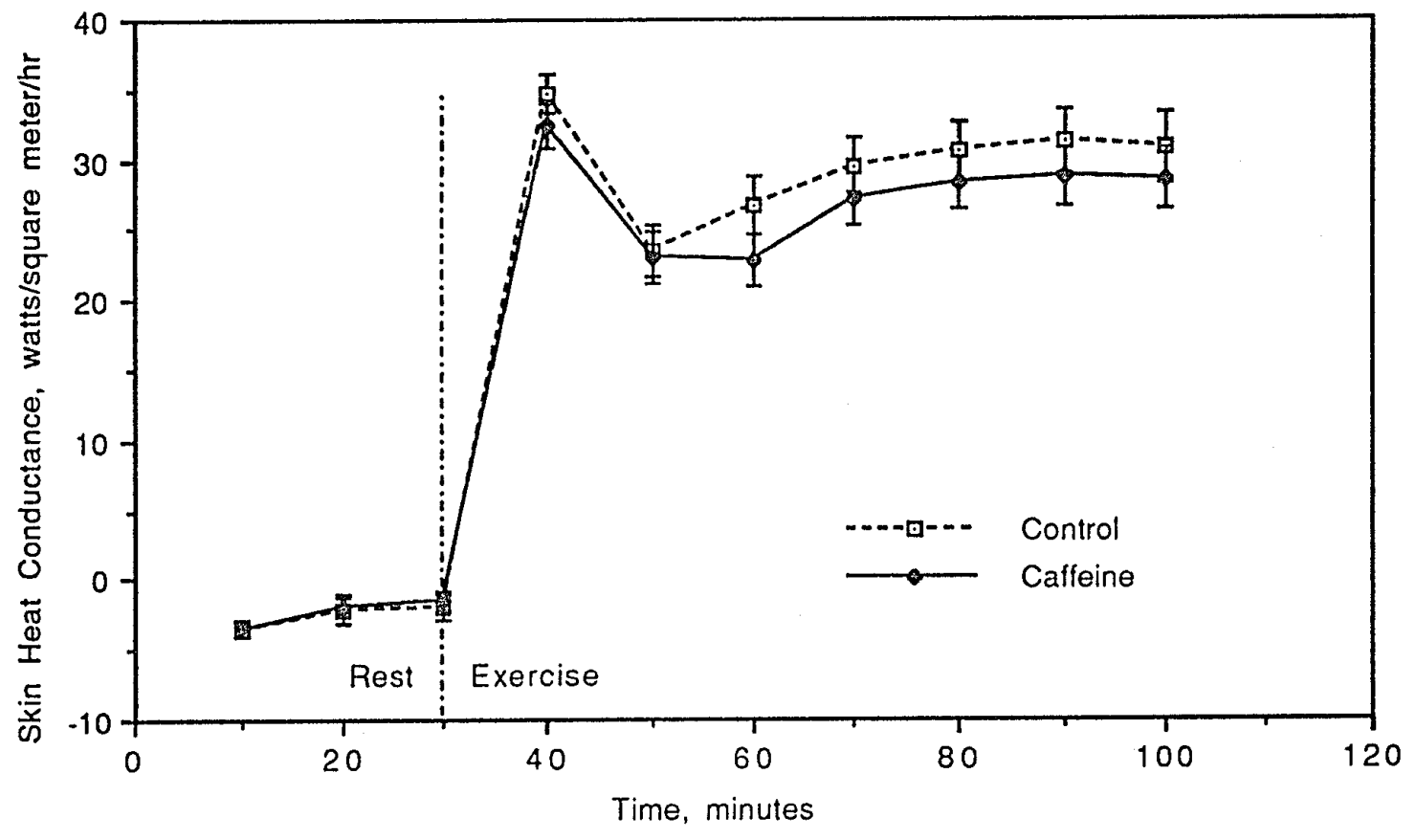

Figure 10. Mean Skin Heat Conductance ( \pm SE) 
minute 40 was significantly greater than minutes at 50 and 60. 


\begin{abstract}
SUMMARY OF FINDINGS
Paired t-tests found no significant differences

between the caffeine session and control session in total

weight loss $(p<.791)$, weight loss in grams per hour

$(p<.788)$, total water loss $(p<.465)$, or total sweat loss

$(p<.465)$.

Summary tables for repeated measures two-way analysis

of covariance applied to oxygen uptake, heart rate, rectal

temperature, mean skin temperature, and skin heat

conductance are found in Appendix G. Oxygen uptake had no

significant differences between sessions (p<.16),

significant differences across time ( $p<.001)$, and a

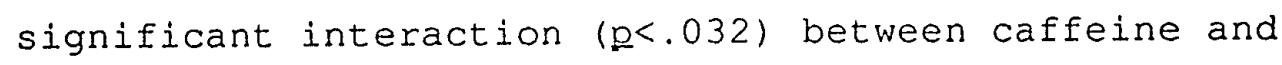

control sessions. Heart rate had no significant

differences between sessions ( $<<.458)$, significant

differences across time $(\underline{p}<.001)$, and a significant

interaction $(\underline{p}<.030)$ for caffeine and control sessions.

Rectal temperature had no significant differences between

sessions $(p<677)$, significant differences across time

$(p<.001)$, and a non-significant interaction $(p<.068)$ for

caffeine and control sessions. Mean skin temperature had

no significant differences between sessions ( $p<.547)$, no

significant differences across time $(p<.069)$, and non-

significant interaction $(p<.886)$ for caffeine and control

sessions. Skin heat conductance had no significant
\end{abstract}


differences between sessions $(p<.232)$, significant differences across time $(\underline{p}<.001)$, and non-significant interaction $(p<.085)$ for caffeine and control sessions.

Repeated measures one-way analysis of variance (ANOVA) and Tukey post-hoc tests determined oxygen uptake, heart rate, rectal temperature, and skin heat conductance to be significantly lower during the resting phase than during the exercise phase. In addition to these differences across time produced by exercise, heart rates at minute 40 (10 minutes into exercise) were significantly lower than at minute 100 (70 minutes into exercise). Rectal temperatures were significantly lower at minutes 40 and 50 than minutes 60 through 100, and minute 60 was significantly lower than minutes 70 through 100 . Skin heat conductance 10 minutes into the exercise phase (minute 40) was significantly greater than 20 and 30 minutes into the exercise phase (minutes 50 and 60).

Significant interaction, between caffeine and control sessions were found for oxygen uptake and heart rate. Oxygen uptake for both sessions were very similar during rest and the first 10 minutes of exercise; then the caffeine session rose slightly above the control session and remained higher until minute 100 where the control session rose slightly to become relatively equal to the caffeine session. Heart rates for the caffeine session 
were below control session heart rates up until minute 50 of data collection. At minutes 50, 60 and 70 , both sessions had very similar heart rates. During minutes 80 and 90 the caffeine session had slightly greater heart rates, and during minute 100 both sessions were once again very similar.

\section{Discussion}

The purpose of this study was to determine if caffeine affects rectal temperature, skin temperature, skin heat conductance, or sweat loss in aerobically trained men at rest and when preforming sub-maximal aerobic exercise under normal ambient conditions. Rectal temperatures at rest and during sub-maximal exercise were not significantly affected by caffeine. This result is in agreement with results of Gorden et al. (1984), Falk et al. (1990), and Biren et al. (1992) who also found no significant effect of caffeine ingestion on rectal temperature. However, it should be noted that at minutes 80,90 , and 100 of the present study, caffeine rectal temperatures were 0.08 to $0.09^{\circ} \mathrm{C}$ higher than the control session. There are several possible causes for this trend toward higher rectal temperatures. oxygen uptake in the caffeine session, although not significantly different, was consistently 0.06 to $0.1 \mathrm{I} / \mathrm{min}$ higher during exercise. Accompanying increases in 
metabolic rate would increase rectal temperature unless the additional heat produced could be dissipated (Santee \& Gonzalez, 1988). Skin temperatures were also consistently 0.38 to $0.50^{\circ} \mathrm{C}$ lower with caffeine. Although these differences were not significant, the lower temperatures during the caffeine session indicate that heat was not being released through increased vasodilation of the skin. Possible dehydration in the caffeine session due to increased urinary flow (O'Neil et al., 1986) may also have attributed to the sight increase in rectal temperature during the final stages of exercise. Our results do not agree with Doubt and Hsieh (1991), where exercise rectal temperature was significantly increased during head out immersion in $28^{\circ} \mathrm{C}$ water. The temperature gradient between the skin and water may not have been great enough to facilitate adequate heat transfer. The difference between evaporative heat loss in the present study and heat loss via convection to $28^{\circ} \mathrm{C}$ water is a likely explanation for the contradictory results between Doubt and Hseih (1991) and the present study.

Mean skin temperatures tended to be lower in the caffeine session for all but the starting temperatures. This trend does not support the findings of Biren et al. (1992) where caffeine significantly increased resting skin temperatures in a normal environment. The reasons for this 
discrepancy in skin temperature cannot be easily explained since caffeine dosage, environmental conditions, and exercise intensities, although not the same, were very similar for both investigations. Because caffeine ingestion acutely increases epinephrine levels (Bangsbo et al., 1992), a vasoconstrictive effect would be expected which could explain the small decrease in skin temperature in the present study.

Tendencies toward higher rectal temperatures during the last 30 minutes of the exercise period and lower skin temperatures observed in the caffeine session, should have produced lower skin heat conductance. Skin heat conductance tended to be lower for the caffeine session during exercise.

Sweat rate was not affected by caffeine, in agreement with Falk et al. (1990), who found that caffeine had a slightly greater sweat rate while the present investigation found a slightly lower sweat rate. The small decrease in sweat rate could be explained by possible vasoconstriction caused by elevated epinephrine levels.

The significant differences observed over time for oxygen uptake, heart rate, rectal temperature, and skin heat conductance were normal physiological responses that occur during exercise. Additional convective and evaporative cooling produced by the fan during exercise prevented skin temperatures from increasing significantly 
during exercise.

Only slight non-significant differences in rectal temperature, skin temperature, heat skin conductance, and sweat rate were observed between and caffeine and control sessions, these differences were not significant.

\section{conclusion}

Under the conditions of this study, a high dosage of caffeine has no detrimental effects on rectal temperature, mean skin temperature, skin heat conductance, or sweat rate during heavy exercise in normal ambient conditions.

\section{Weaknesses}

Blood samples were not drawn during this investigation so plasma caffeine levels, plasma volume, and epinephrine levels could not be established. Because plasma caffeine levels were not ascertained it is difficult to determine if an adequate amount of time elapsed for caffeine absorption to take place before exercise data collection occurred. Data derived from plasma volume would have produced information on hydration levels.

Rectal temperatures did not plateau in this study, indicating that a longer exercise period may have produced higher final rectal temperatures. It should be noted that most of the subjects in the present study probably would 
not have been able to complete a much longer exercise session.

\section{Recommendations for Future Research}

Because of the trends toward higher rectal temperatures near the end of exercise in the caffeine session future studies should incorporate longer exercise periods. Stressing the thermoregulatory system via exercise in a hot environment would also be recommended. Biren et al. (1992) found that caffeine had no significant effect on rectal temperature during exercise in the heat, but the exercise lasted only 60 minutes. Research incorporating marathon conditions and durations in a hot environment could be conducted to establish the effects of caffeine on thermoregulation under these conditions that cause greater stress for the thermoregulatory system. 
References

American College of Sports Medicine (1991). Guidelines for exercise testing and prescription. Philadelphia: Lea \& Febiger.

Arogyasami, J., Yang, H. T., \& Winder, W. (1989). Effect of caffeine on glycogenolysis during exercise in endurance trained rats. Medicine and Science in sports and Exercise, 21 (2), 173-177.

Astrand, P., Rodahl, K. (1986). Textbook of Work

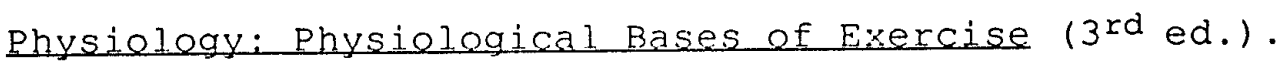
San Francisco: McGraw-Hill.

Bangsbo, J., Jacolben, D., Nordberg, N., Christensen, N. J., \& Graham, T. (1992). Acute and habitual caffeine ingestion and metabolice responses to steady-state exercise. Journal of Applied Physiology, 22(4), 12971303.

Beckman, H. (Ed.). (1961). The Nature, Action and Use of Drugs (2nd ed.). Philadelphia: W. B. Saunder Co. Biren, G., Al-Refaee, S., Einck, A., Paolone, A. (1992). The effect of heat and caffeine on metabolism and body temperature. Medicine and science in sports and Exercise, 24(9), S63. (Abstract No. 374) 
Bond, V., Adams, R., Balkisson, B., McRae, J., Knight, E., Ribbins, S., \& Banks, M. (1987). Effects of caffeine on cardiorespiratory function and glucose metabolism during rest and graded exercise. Journal of Sports Medicine and Physical Fitness, 27(1), 47-52.

Borstel, W. R., Wurtman, R. J. (1984). Caffeine and the cardiovascular effects of physiological levels of adenosine. In P. B. Dews (Ed.). Caffeine: perspectives from recent research (pp. 142-150). Washington, DC: International Life Sciences Institute.

Brozek, J. F., Grand, J. T., Anderson, J., \& Keys, A. (1963). Densiometric analysis of body composition: Revision of some quantitative assumption. Annals of the New York Academy of Science, 110, 113-140.

Chad, K., \& Quigley, B., (1989). The effects of substrate utilization, manipulated by caffeine, on post-exercise oxygen consumption in untrained female subjects. European Journal of Applied Physiology, 59, 48-52.

Christensen, C. (1990). HuP 154A Christensen Fall 1990 Course Reader, San Jose State University (Available from Associated students print shop, San Jose, CA)

Chung, S. H. (1986). Effects of caffeine ingestion on Iipid metabolism of females during submaximal exercise performance. Unpublished master's thesis, San Jose State University, CA. 
Cisar, C. J., Johnson, G. O., Fry, A. C., Housh, T. J., Hughes, R. A., Ryan, A. J., \& Thorland, W. G. (1987). Preseason body compostion, build, and strength as predictors of high school wrestling success. Journal of Applied Sperts Science Research, 4, 166-170.

Costill, D. I. Dalsky, G. P., \& Fink, W. J. (1978). Effects of caffeine ingestion on metabolism and exercise performance. Medicine and Science in Sports, 10(3), 155158 .

Doubt, T. J., Hsieh, S. S. (1991). Additive effects of caffeine and cold water during submaximal leg exercise. Medicine and Science in Sports and Exercise, 23(4), 435442 .

Dullo, A. G., Geissler, C. A., Horon, T., Collins, A., \& Miller, D. S. (1989). Normal caffeine consumption: influence on the thermogenesis and daily energy expenditure in lean and postobese human volunteers. The American Journal of Clinical Nutrition, 49(1) 44-50.

Dullo, A. G., Miller, K. S. (1986). The thermogenic properties of ephedrine/methlxanthine mixtures: human studies. Internal Journal of obesity, 10, 467-481. Ekblom, B., Greenleaf, C. J., Greenleaf, J. E., Hermansen, L. (1971). Temperature regulation during continuous and intermittent exercise in man. Acta Physiology Scandinavia, 81, 1-10. 
Falk, B., Burstein, R., Rosenblum, G., Shapiro, Y., ZylberKatz, E., \& Bashan, N. (1990). Effects of caffeine ingestion on body fluid balance and thermoregulation during exercise. Canadian Journal of Physiology and Pharmacology, 68, 889-892.

Falk, B., Burstein, R., Ashkeazi, I., Spilberg, O., Alter, J., Zylber-Katz, I., Rubinstein, A., Bashan, N., \& Shapiro, Y. (1989). The effect of caffeine ingestion on physical performance after prolonged exercise. European Journal of Applied Physiology, 59, 168-173.

Fernstrom, J. D., Fernstrom M. H. (1984). Effects of caffeine on monoamine neurotransmitters in the central and peripheral nervous system. In P. B. Dews (Ed.). Caffeine: perspectives from recent research (pp. 107118). Washington, DC: International Life Sciences Institute.

Fisher, S. M., McMurray, R. G., Berry, M., Mar, M. H., Forsythe, W. A. (1986). Influence of caffeine on exercise performance in habitual coffie users. International Journal of Sports Medicine, I, 276-280. Gonzalez, R. R., Berglund, L. G., \& Gagge, A. P. (1978). Indices of thermoregulatory strain for moderate exercise in the heat. Journal of Applied Physiology, 44(6), 889899. 
Gordon, N. F., Myburgh, J. L., Kruger, P. E., Kempff, P. G., Cillers, J. F., Moolman, J., \& Grobler, H. C. (1982). Effects of caffeine ingestion on thermoregulatory and myocardial function during endurance performance. South African Medical Journal, $\underline{62}(18), 644-647$.

Govoni, L., Hanys J. (Eds.). (1978). Drugs and Nursing Implications ( $3^{\text {rd }}$ ed.). Appleton-Century Crofts. Graham, T. E., Sathasivam, P., MacNaughton, K. W. (1991). Influence of cold, exercise, and caffeine on catecholamines and metabolism in men. Journal of Applied Physiology, 70(5), 2052-2058.

Graham, T. E., \& Spriet, L. L. (1991). Performance and metabolic responses to a high caffeine dose during prolonged exercise. Journal of Applied Physiology, 71(6), 2292-2298.

Grayson, J., \& Kuehn, L. A. (1979). Heat transfer and heat loss. In P. Lomax and E. Schonbaum (Eds.) Body Temperature: Regulation, Drug Effects, and Therapeutic Implications (pp.71-88). New York: Marcel Dekker. Greenleaf, J. E., and Castle, B. L. (1972). External auditory canal temperature as an estimate of core temperature. Journal of Applied Physiology, 32, 194-198. 
Greenleaf, J. E., Reese, R. D. (1980). Exercise thermoregulation after 14 days of bed rest. Journal of Applied Physiolegy, 48(1), 72-78.

Jackobson, B. G., Kulling, E. A. (1989). Health and ergogenic effects of caffeine. British Journal of Sports Medicine, 23(1), 34-40.

Jequier, E. (1987). Energy utilization in human obesity. New York Academy of Sciences, Annals, 49(9), 73-83. Lang, P. B., Latin, R. W., Berg, K. E., Mellion, M. B. (1992). The accuracy of the ACSM cycle ergometry equation. Medicine and Science in sports and Exercise, $\underline{24}(2), 272-276$

LeBlanc, J., Jobin, M., Cote, J., Samson, P., \& Labrie, A. (1985). Enhanced metabolic response to caffeine in exercise-trained human subjects. Journal of Applied Physiology, 59(3), 832-837.

Lin, M. T., Chandra, A., \& Liu, G. G. (1980). The effects of theophylline and caffeine on thermoregulatory functions of rats at different ambient temperatures. Journal of Pharmacy and Pharmacology, 32, 204-208.

Lind, A. R. (1963). A physiological criterion for setting thermal environmental limits for everyday work. Journal ef Applied Physiology, 18(1), 51-56.

Kastrup, E. (Ed.). (1984). Drug: facts and comparisons (pp. 778-779). St. Louis: J. B. Lippincott Co. 
McNaughton, L. R. (1986). The influence of caffeine ingestion on incremental treadmill running. British Journal of Sports Medicine, 20(3), 109-112.

Nielsen, M. (1970). Heat production and body temperature during rest and exercise. In J. D. Hardy, A. P. Gagge, \& J. A. J. Stolwijk (Ed.), Physiological and Behavioral Temperature Regulation (pp. 205-214). Springfield, IL: Charles C Thomas.

O'Neil, F.T., Hynak-Hankinson, Mo.T., \& Gorman, J. (1986). Research and application of current topics in sports nutrition. American Dietetic Association Journal, 8.

Pandolf, K. B., Sawka, M. N., \& Gonzalez, R. R. (Eds.). (1988). Human Performance Physiology and Fnvironmental Medicine at Terrestrial Extremes. Indianapolis: Benchmark Press.

Pincomb, G. A., Wilson, M. F., Bong Hee Sung, Passey, R. B., Lovalio, W. R. (1991). Effects of caffeine on pressor regulation during rest and exercise in men at risk for hypertension. American Heart Journal, 122, $1107-1115$

Powers, S. K., \& Dodd, S. (1985). Caffeine and endurance performance. Sports Medicine, 2, 165-174. 
Rall, W. T. (1985). Central nervous system stimulants. In Gilman, A. G., Goodman, L. S., Rall, T. W., \& Murad, E. (Eds.), Geodman and Gilman's the Phamacological Basis of Therapeutics (pp. 589-603). New York: MacMillan.

Robertson, D., Curatolo, P. W. (1984). The cardiovascular effects of caffiene. In P. B. Dews (Ed.). Caffeine: perspectives from recent research (pp. 77-85). Washington, DC: International Life Sciences Institute. Rosenbloom, D., \& Sutton, J. R. (1985). Drugs and exercise. Medical Clinics of North America, $89(1), 177-187$. Saltin, B., Hermansen, L. (1966). Esophageal, rectal, and muscle temperature during evercise. Journal of Applied Physielogy, 21(6), 1757-1762.

Santee, W. R., \& Gonzalez, R. R. (1988). Characteristics of the thermal environment. In Pandolf, K. B., Sawka, M. N., \& Gonzolez, R. R. (Eds.), Human Performance, Physiology, and Environmental Medicine at Terrestrial Extremes (pp.1-43). Indianapolis: Benchmark.

Sasaki, H., Maeda, J., Usui, S., \& Ishiko., T. (1987). Effect of sucrose and caffeine ingestion on performance of prolonged stremuous running. International Journal of Sports Medicine, 8(4), 261-165. 
Sawka, M. N., \& Wenger, B. C. (1988). Physiological responses to acute exercise-heat stress. In $K . B$. Pandolf, M. N. Sawka, and R. R. Gonzalez (Ed.). Human Performance Physiology and Environmental Medicine at Terrestial Extremes (pp. 97-151). Indianapolis: Benchmark Press.

Schottelius, B. A., \& Schottelius, D. D. (1978). Textbook ef Rhysiology ( $8^{\text {th }}$ ed.). Saint Louis: C. V. Mosby Co. Schlosberg, A. J. (1983). Temperature responses in rats after acute and chronic administration of caffeine. Pharmacology Biochemistry and Behavior, 18(6), 935-942. Snyder, S. H. (1984). Adenosine as a mediator of the behavioral effects of xanthines. In P. B. Dews (Ed.), caffeine: perspectives from recent research (pp.129141). Washington, DC: International Life Sciences Institiute.

Somani, S. M., \& Gupta, P. (1988). Caffeine: A new look at an age old drug. International Journal of Clinical Pharmacology, Therapy and Toxicology, 26(11), 521-533. Starkenstein, E. (1927). Wasserhaushalt und durststillung [Water metabolism and the quenching of thirst]. Klinische Wochenschrift, $\underline{6}(4), 147-152$. Stein, J., Hauck, C. H., Su, P. Y. (EdS.). (1982). The Random House College Dictionary: Revised Edition. New York: Random House Inc. 
Stephenson, L. A., \& Kolka, M. A. (1988). Effect of gender, circadian period and sleep loss on thermal responses during exercise. In K. B. Pandolf, M. N. Sawka, \& R. R. Gonzalez (Ed.). Human Performance Physiology and Environmental Medicine at Terrestrial Extremes (pp. 267304). Indianapolis: Benchmark Press.

Stolwijk, J. A. J., Saltin, B., Gagge, A. P. (1968). Physiological factors associated with sweating during exercise. Aerospace Medicine, 39, 1101-1105. Tarnopolsky, M. A., Atkinson, S. A., MacDougall, J. D., Sale, K. G., \& Sutton, J. R. (1989). Physiological responses to caffeine during endurance running in habitual caffeine user. Medicine and Science in Sports and Exercise, 21 (4), 418-424.

Toner, M. M., McArdle, W. D. (1988). Physiological adjustments of man to the cold. In K. B. Pandolf, M. N. Sawka, \& R. R. Gonzalez (Eds.), Human performance physiology and environmental medicine at terrestrial extremes (pp.361-400). Indianapolis: Benchmark Press Inc.

Vallerand, A. L., Jacobs, I., \& Kavanagh, M. F. (1989). Mechanism of enhanced cold tolerance by and ephedrinecaffeine mixture in humans. Journal of Applied Physiology, 67, 438-444. Winder, W. (1986). Effect of intravenous caffeine of liver 
glycogenolysis during prolonged exercise. Medicine and

Science in Sports and Exercise, 18(2), 192-196. 
APPENDIX A

HEALTH AND EXERCISE HISTORY QUESTIONNAIRE

Name

Date Occupation

Work phone Home phone

Work address

Home address

Physician name

Physician phone

Age __years Weight____ lbs. Height____ in.

Gender

Times you could be available for testing at sJSU.

Sunday

Monday

Tuesday

Wednesday

Thursday

Friday

Saturday (am) $(\mathrm{pm})$

Medical History

Place a check next to any of the conditions that you have experienced.
() Heart attack
() Cardiac surgery
() Rapid heart beats
() Unusual cardiac finding
() Stroke
() Abnormal blood Lipids
() Anemia
() Limp
() Coronary angioplasty
() Chest discomfort
() Heart murmurs
() High blood pressure
() Ankle swelling
() Diabetes
() Orthopedic problems, arthritis
() Asthma, emphysema or bronchitis
() Lightheadedness or fainting with exercise
() Shortness of breath with exercise 
Please explain any of the above that you have experienced and give dates of occurrence.

() Medications of any type

What kind of medications

() Recent illness, hospitalization, or surgical procedure Explain

() Drug allergies

Explain

\section{Eamily History:}

() Coronary disease

Relation, and age of death

() Sudden death

Relation, and age of death

() Lipid abnormalities

Relation, and age of death

ether Dietary Practices:

() Caffeine consumption

Coffee cups/day cups/week

Colas cups/day cups/week

Chocolate bars/day cups/week

Other

() Alcohol use

Approximately how much alcohol do you consume each day?

Smoking History:

() Smoke less than 5 cigarettes/day

() Smoke less than $1 \mathrm{pack} / \mathrm{day}$

() Smoke more than $1 \mathrm{pack} / \mathrm{day}$

() Have never smoked

() Use to smoke but have quit When did you quit?

() Do you have any eating disorders? 
Explain

\section{Exercise Histery:}

How often do you exercise?

() 0 to 1 times/week

() 2 times/week

() 3 to 5 times/week

() More than 5 times/week

How long are your exercise periods?

() 0 to 15 minutes () 16 to 29 minutes () 30 to 45 minutes

() 46 to 60 minutes () more than sixty minutes

Place an $\mathrm{X}$ in the types of evercise you participate in regularly.

$$
\text { Frequency/week Duration (min), }
$$

() Cycling

() Walking

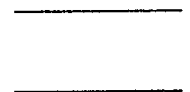

() Jogging

() Swimming

() Rowing

() Aerobics

Other (explain)

What do you consider your body type to be?

() lean

() average weight

() slightly over weight

() over weight 
APPENDIX B

EFEECTS OE CAFEEINE ON THERMOREGULATTON OE ACTIVE MEN

AT REST AND EXERCISE.

\begin{abstract}
STATEMENT OF INEORMED CONSENT FOR OBTAINING
MEASUREMENTS OF: MAXIMUM OXYGEN UPTAKE, BODY COMPOSITION, RECTAL, AND SKIN TEMPERATURES.

Purpese of the study The purpose of this study is to observe caffeine's effect on sweat loss, skin (surface) temperature, rectal temperature, mean body temperature, skin heat conductance, and heart rate during rest and exercise.
\end{abstract}

Invitation to Participate

You are being invited to participate in a thesis project. The purpose of this research is to determine if caffeine effects temperature regulation during rest and exercise. Your participation is voluntary, and you can choose not to participate at any time during the project. This experiment will require the completion of three trials within two weeks. The first trial (approximately one hour) will assess your maximum oxygen uptake, body composition (fat percentage), and height. The second and third trials (approximately two and a half hours) will be the same except one trial will have caffeine (in a dose equal to 10 milligrams of caffeine per kilogram of body weight) added to the drink that will be taken before the resting and bicycling period. All the experiments will be conducted at the San Jose State university campus.

\title{
Basis for selection
}

You have been selected because you are: a healthy male, between the ages of 18 and 40 years old, relatively lean, and exercise aerobically at least three times per week for 30 minutes or more. If you decide to participate, your response to a health history questionnaire will be reviewed by an exercise physiologist and, if satisfactory, you will be asked to participated in the tests described below. 


\section{Explanation of Procedures}

Body Composition (Fat Percentage)-(approximately 30 minutes) Underwater weighing requires three measurements:

residual lung volume (air left in the lungs after a maximal exhalation), body weight while under water, and normal body weight. Height will also be taken at this time. To measure residual lung volume you will be breathing room air through a mouthpiece. At the end of a normal expiration a valve will be turned so you will be breathing a mixture of helium and room air from a spirometer. Oxygen will be added to the spirometer when needed. After breathing this gas mixture for several minutes a maximal inhaled and exhale breath will be recorded. Several measurements may need to be taken.

To measure underwater weight you will be sitting on a sling so you are positioned neck deep in 820 to $850 \mathrm{~F}$ water. After being completely submerged under the water you will need to exhale as much air as possible and remain under water for five to ten seconds as the measurement is taken. This underwater weight will be measured six to ten times with rest periods allow between measures.

Maximal exygen Uptake (approximately 30 minutes)

Maximal oxygen uptake will be determined using a cycle ergometer at a pedal cadence of 60 repetitions per minutes (rpm). After a five minute warm-up at a power output of 180 kilopond meters per minute ( $\mathrm{km} / \mathrm{min})$, the resistance will be increased by $180 \mathrm{kpm} / \mathrm{min}$ every minute until you are unable to maintain the $60 \mathrm{rpm}$ speed Throughout this maximal test, blood pressure will be measured every minute, where respiratory parameters and heart rate will be monitored continuously.

\section{Caffeine/Non-Caffeine Trials (approximately two and a half} hours each)

As mentioned previously these trials will be the same except one trial will have caffeine added (in a dose equal to 10 milligrams of caffeine per kilogram of body weight) to a diet drink mixture and the other trial will not have caffeine added. Before both of these trials you will be required to not eat or drink any caffeine for four days before the test. During these trials skin temperature will be measured using skin probes that will be held on with elastic bands; rectal temperature will be measured using a rectal probe; ventilation will be measured which will require you to oreath into a mouth piece; and heart rate will be monitored which will require electrode application.

After drinking the liquid you will sit on a chair for 30 minutes while temperatures, respiration, and heart rate are recorded every ten minutes. These measurements will continue into the exercise phase, where you will pedal the ergometer 
at a rate and resistance equal to $65 \%$ of you maximal work capacity. A fan will blow air on you as you complete 70 minutes of cycling.

\section{Risks and Discomforts}

\section{Underwater Weighing}

Although the water quality in the tank is maintained daily there is still a possible risk of infection from the water. This risk is small since the water is chemically treated and filtered daily. As with most pool underwater experiences there is a chance of chlorine irritation, swallowing water, and choking.

Residual Lung Volume

There may be some discomfort from the nose clip and from breathing through the mouthpiece. Some people experience dizziness and lightheadedness when preforming breathing measurements.

Maximal Oxygen Uptake

There will be some discomfort that is common with high levels of exercise in this test: sweating, increased heart rate, increased breathing rate, elevated blood pressure, and fatigue. You may experience dryness in the mouth, throat, and chest. Toward the end of this maximal test you may incur abnormal blood pressure, fainting, dizziness, muscle cramps, muscle fatigue, and abnormalities in heart beat. You may feel lightheaded and slightly nauseous for a short while following the test. If abnormalities are detected in pulmonary function, electrocardiographic recordings, or if other abnormal physiological signs occur the test will be stopped and you will be asked not to continue the rest of the experiment.

Caffeine Effects/Caffeine Withdrawal

Adverse reactions to caffeine ingestion can include: restlessness, irritability, nervousness, insomnia, headache, nausea, vomiting, elevated blood glucose, tingling of the face, flushing, an increase or decrease in heart rate, and muscle twitching. At the dosage applied in this study caffeine may occasionally cause cardiac irregularities. Habitual caffeine consumers may experience headaches after being deprived of caffeine.

Sixty-Five Percent Bicycling work Ioad

During this test you will experience the same types discomfort as you would during heavy exercise: sweating, 
increased heart rate, increased breathing rate, elevated blood pressure, and fatigue. You may experience lightheadedness and dryness in the mouth, throat, and chest.

\section{Benefits from Participating in this study}

You will benefit from this study by receiving information about your body fat percentage and maximal oxygen consumption. If you are a caffeine user you may be interested in how caffeine effects your body temperature.

\section{Assurance of confidentiality}

The information that will be obtained will be treated as privileged and confidential and will not be released or revealed without your expressed written consent. The data obtained, however, may be used for a statistical or scientific purpose with your right of privacy retained. Your right to confidentiality will be protected.

\section{Withorawal from the Study}

Your participation in this research is voluntary. You may withdraw from this study at any time (including during a test) without prejudice. You may also decline to answer any question or item on the health history questionnaire. Maximal oxygen consumption testing will be supervised and conducted a Certified Exercise Test Technologist. Certified CPR personnel will also be present during all testing.

If you have any questions about this research feel free to ask them. If questions come up later or in case of an emergency please contact me (Nancy Dunagan) at (408) 248-7578 or Dr. Craig Cisar (408) 924-3018. In case there is a complaint you can contact Dr. Craig Cisar (408) 924-3018. If there are questions about research subject's rights, or in the event of research-related injury you may contact Dr. Serena Stanford, Associate Academic Vice President of Graduate Studies and Research at (408) 924-2480. 


\section{AGREEMENT TO PARTICIPATE IN RESEARCH}

SAN JOSE STATE UNIVERSITY

RESPONSIBLE INVESTIGATOR: Nancy A. Dunagan

TITLE OF PROTOCOL: Effects of Caffeine on Thermoregulation of Active Men at Rest and Exercise.

\section{consent}

By signing this form, I agree that:

(a) I have read the information provided above and have decided to participate in this study;

(b) I understand the discomforts and risks involved;

(c) I understand that I can withdraw from this study at any time without prejudice to my relations with SJSU.

(d) I understand that my identity will be kept confidential.

(e) I understand that I may ask questions about this study at any time.

SIGNATURE OF SUBJECT

DATE

PRINTED NAME

SIGNATURE OF WITNESS

SIGNATURE OF INVESTIGATOR 
APPENDIX C

RESIDUAL LUNG VOLUME

AND UNDERWATER WEIGHING DATA SHEET

Name

Vital Capacity (L)

Starting lung volume (VC $+.5 \mathrm{~L})$

Initial N2 reading after purging spirometer $\left(\frac{\circ}{0}\right)$ trial 1 trial 2 trial 3

average

** (ADD STARTING LUNG VOLUME) **

N2 reading at end expiration of room air $\left(\frac{\circ}{0}\right)$

N2 reading at equilibrium during fast hard breathing (\%)

N2 reading at end expiration after rebreathing technique (\%)

Temperature of expired air $\left({ }^{\circ} \mathrm{C}\right)$ BTPS

Body Weight (KG)

Height $\mathrm{cm}$

Under Water body weight (KG)

Average of three highest underwater weight scores within $.05 \mathrm{~kg}$ of each other (KG)

Harness weight (KG)

Water temperature (F) Min fat 1 Max $\mathrm{fat} \underline{18}$

Water density (KG/L) 
APPENDIX D

\section{List of Caffeine Sources}

The following are caffeine containing foods and drinks that you should not have for four days prior to the test. If you accidentally do have some caffeine please contact Nancy Dunagan (408-248-7578) to re-schedule the test date. Please, read the content labels of the food and drink you ingest to double check and make sure caffeine does not go into your body. Your system needs to be clean from caffeine in order to obtain accurate results in this experiment.

Drinks

Coffee of any type (not even decaffeinated)

Tea of any type

Cola of any type

$\mathrm{Tab}$

Mr. Pibb

Dr. Pepper

Aspen

Mellow Yellow

Cocoa of any type Chocolate of any type

Food

Candies and cookies containing chocolate and cocoa

Check packages on frozen dairy products for caffeine

Check gelatin and puddings for caffeine

Drugs - Prescription

APC's (Aspirin, Phenacetin, Caffeine)

Cafergot

Darvon

Fiorinal

Migral

Over the counter drugs

Vanguish, Excedrin

Ban-Drowz

Extra Strength Excedrin Tirend

No-Doz

Vivarin

Appendirne

Caffedrine

Kirkaffeine

Quick Pep

Dexatrim

Dristan

Anacin, Aspirin compound, Bromoselter

Cope, Emperin compound, Midol

These lists were derived from Chung (1986), Kastrup (1989), and from Jacobson and Kulling (1989). 


\section{APPENDIX E ADVERTISEMENT TO SOLICT SUBJECTS}

EEFECTS OF CAFEEINE ON THERMOREGULATION OF ACTIVE MEN

AT REST AND EXERCISE.

Are you interested in finding out your fat percentage and maximum oxygen consumption? You could have these measurements made free of charge and at the same time contribute to scientific research. To volunteer for this study you need to be:

MALE

BETWEEN 18 AND 40

AVERAGE TO LEAN BODY TYPE

EXERCISE AEROBICALLY AT LEAST 3 TIMES PER WEEK (CYCLE, JOG, ETC.) FOR AT LEAST 30 MINUTES EACH EXERCISE SESSION

TIME REQUIREMENT:

1 - 2 hour session and

$2-2.5$ hour sessions

If you are interested in helping with data collecting, or volunteering to be a subject call Nancy Dunagan at (408) 248-7578 to find out more about the study. There is no obligation. Participation in this research is on a voluntary basis. 


\section{APPENDIX E, DATA COLLECTION SHEETS \\ CAEFEINE/NON CAFFEINE TRIAL 1 OR 2}

Name

ENVIRONMENTAL TEMPERATURE.

Wet bulb temp (sling psychrometer) two lowest agreeing temp ${ }^{\circ} \mathrm{C}$

Dry bulb temp _ ${ }^{\circ} \mathrm{C}$

Relative humidity

Barometric pressure

STPD (standard temp \& press dry)

STPD sat

BTPS (Body tem \& press sat)

Pre-exercise weight

Oral Temperature 1 pre-exercise

-Blindfold and put a nose clip on subject. Drink mixture should be $37^{\circ} \mathrm{C}$ of $237 \mathrm{ml}(80 \mathrm{z})$ lemonade.

-Drink temperature

Wind speed

Post-exercise weight

Oral Temperature 2 post exercise 
Name Date

Test \#1 or \#2

Resting Time starts upon completion of drinking the beverage. Give volunteer one minute to drink liquid.

\begin{tabular}{|c|c|c|c|c|c|c|c|}
\hline Time & Rect \# 1 & Chest \#3 & Back $\# 4$ & FArm $\# 6$ & Calf\#8 & UArm\#9 & Thigh\#10 \\
\hline$\overline{l m}$ & & & & & & & \\
\hline $5 \mathrm{~m}$ & & & & & & & \\
\hline$\overline{10 m}$ & & & & & & & \\
\hline$\overline{20 m}$ & & & & & & & \\
\hline$\overline{29 m}$ & & & & & & & \\
\hline Exer & cise Bec & ins at & $30 \mathrm{~m}$ & & & & \\
\hline$\overline{35 m}$ & & & & & & & \\
\hline$\overline{40 m}$ & & & & & & & \\
\hline $50 \mathrm{~m}$ & & & & & & & \\
\hline$\overline{60}$ & & & & & & & \\
\hline$\overline{70}$ & & & & & & & \\
\hline$\overline{80}$ & & & & & & & \\
\hline$\overline{90}$ & & & & & & & \\
\hline 100 & & & & & & & \\
\hline
\end{tabular}

cool down 
GAS ANALYSIS AND HEART RATE DURING CAF/NON CAF TRIALS

NAME DATE

\begin{tabular}{l|l|l|l|l|} 
TRIAI 1 OR & $\mathrm{VO}_{2}$ & $\mathrm{VCO}_{2}$ & HEART RATE \\
TIME & & & & \\
\hline TAKE DRINK & & & & \\
\hline $\begin{array}{l}\text { POST DRINK } \\
\text { MIN }\end{array}$ & & & & \\
\hline 2 MIN & & & & \\
\hline 3 MIN & & & & \\
\hline 8 MIN & & & & \\
\hline 9 MIN & & & & \\
\hline $10 \mathrm{MIN}$ & & & & \\
\hline $18 \mathrm{MIN}$ & & & & \\
\hline $19 \mathrm{MIN}$ & & & & \\
\hline $20 \mathrm{MIN}$ & & & & \\
\hline $28 \mathrm{MIN}$ & & & & \\
\hline $29 \mathrm{MIN}$ & & & & \\
\hline $30 \mathrm{MIN}$ & & & & \\
\hline
\end{tabular}


GAS ANALYSIS AND HEART RATE DURING CAF/NON CAE TRIALS

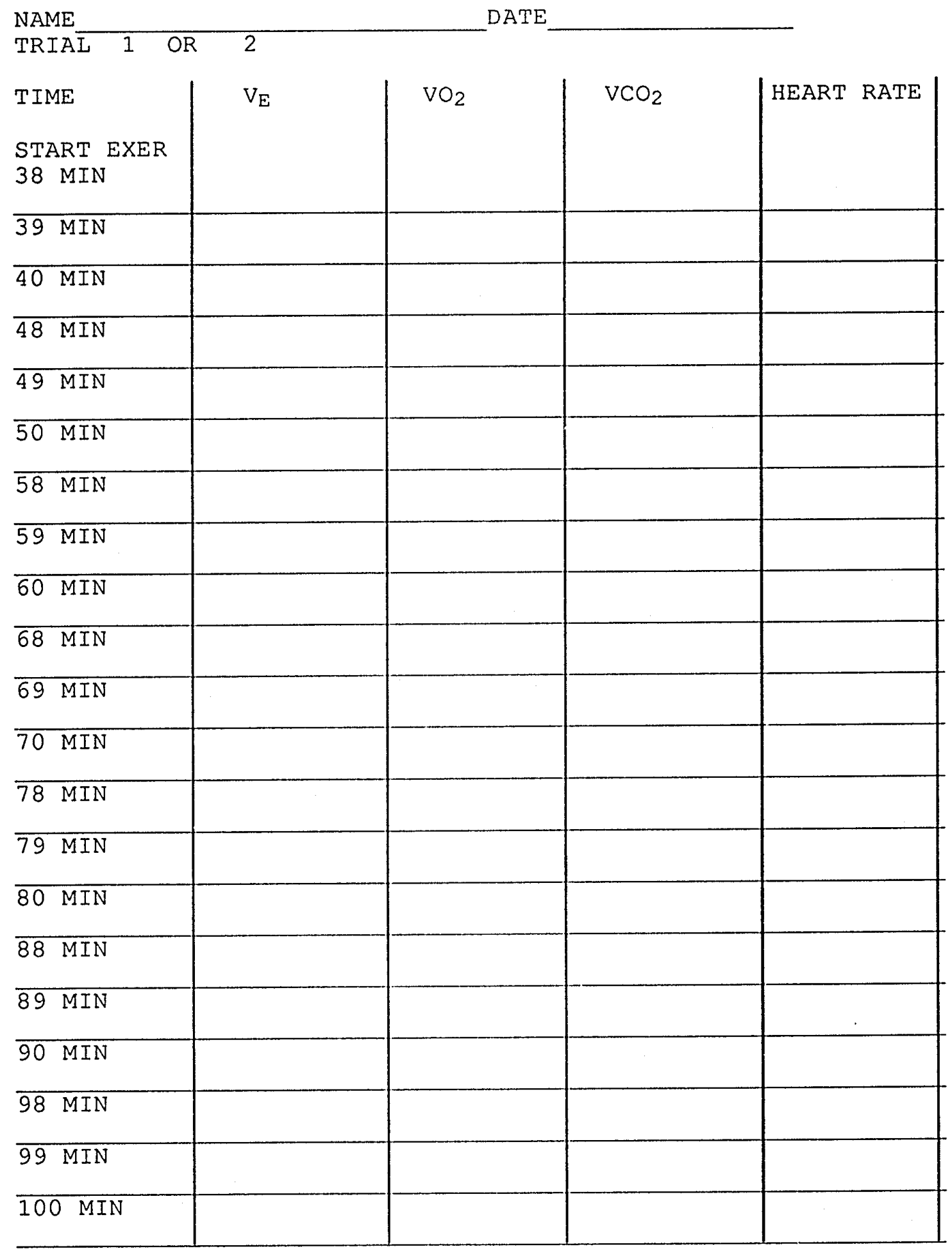


APPENDIX G-1.

Repeated Measures Two Way Analysis of Covariance Summary Table for Oxygen Uptake.

$\begin{array}{lccccc}\text { SOURCE } & \text { SS } & \text { DE } & \text { MS } & F & \text { SIGNIFICANCE } \\ \begin{array}{l}\text { Within } \\ \text { Cells }\end{array} & .34 & 9 & .04 & & \\ \text { Caffeine } & .09 & 1 & .09 & 2.35 & .160\end{array}$

\begin{tabular}{llllll} 
SOURCE & SS & DE & MS & F & SIGNIFICANCE \\
$\begin{array}{l}\text { Within } \\
\text { Cells }\end{array}$ & 4.62 & 100 & .05 & & \\
Time & 266.48 & 10 & 26.65 & 577.03 & .000 \\
\hline
\end{tabular}

\begin{tabular}{lccccc} 
SOURCE & SS & DF & MS & $F$ & SIGNIFICANCE \\
$\begin{array}{l}\text { Within } \\
\text { Cells }\end{array}$ & .51 & 100 & .01 & & \\
Interaction & .11 & 10 & .01 & 2.09 & .032 \\
\hline
\end{tabular}


APPENDIX G-2.

Repeated Measures Two Way Analysis of Covariance Summary Table for Heart Rate.

\begin{tabular}{llllll} 
SOURCE & SS & DF & MS & F & SIGNIF ICANCE \\
$\begin{array}{l}\text { Within } \\
\text { Cells }\end{array}$ & 1006.99 & 9 & 111.89 & & \\
Caffeine & 67.37 & 1 & 67.37 & .605 & .458 \\
\hline
\end{tabular}

\begin{tabular}{lllcll} 
SOURCE & SS & DF & MS & F & SIGNIFICANCE \\
$\begin{array}{l}\text { Within } \\
\text { Cells }\end{array}$ & 10627.67 & 100 & 106.28 & & \\
Time & 384786.79 & 10 & 38478.68 & 362.06 & \\
\hline
\end{tabular}

\begin{tabular}{llllll} 
SOURCE & SS & DF & MS & $F$ & SIGNIF ICANCE \\
$\begin{array}{l}\text { Within } \\
\text { Cells }\end{array}$ & 1866.77 & 100 & 18.67 & & \\
Interaction & 394.62 & 10 & 39.46 & 2.11 & .030 \\
\hline
\end{tabular}


APPENDIX $G-3$.

Repeated Measures Two Way Analysis of Covariance

Summary Table for Mean Rectal Temperature.

\begin{tabular}{lccccc} 
SOURCE & SS & DF & MS & $F$ & SIGNIFICANCE \\
$\begin{array}{l}\text { Within } \\
\text { Celis }\end{array}$ & .74 & 9 & .08 & & \\
Caffeine & .02 & 1 & .02 & .19 & .677 \\
\hline
\end{tabular}

\begin{tabular}{llllll} 
SOURCE & SS & DE & MS & F & SIGNIFICANCE \\
$\begin{array}{l}\text { Within } \\
\text { Celis }\end{array}$ & 6.27 & 90 & .07 & & \\
Time & 78.25 & 9 & 8.69 & 124.85 & .000 \\
\hline
\end{tabular}

\begin{tabular}{llllll} 
SOURCE & SS & DE & MS & F & SIGNIFICANCE \\
$\begin{array}{l}\text { Within } \\
\text { Cells }\end{array}$ & 1.06 & 90 & .01 & & \\
Interaction & .20 & 9 & .02 & 1.86 & .068 \\
\hline
\end{tabular}


APPENDIX G-4.

Repeated Measures Two Way Analysis of Covariance

Summary Table for Mean Skin Temperature.

\begin{tabular}{llllll} 
SOURCE & SS & DF & MS & F & SIGNIFICANCE \\
$\begin{array}{l}\text { Within } \\
\text { Cells }\end{array}$ & 7.63 & 9 & .85 & & \\
Caffeine & .33 & 1 & .33 & .39 & .547 \\
\hline
\end{tabular}

\begin{tabular}{llllll} 
SOURCE & SS & DE & MS & F & SIGNIFICANCE \\
$\begin{array}{l}\text { Within } \\
\text { Cells }\end{array}$ & 42.41 & 90 & .47 & & \\
Time & 7.88 & 9 & .88 & 1.86 & .069 \\
\hline
\end{tabular}

\begin{tabular}{llllll} 
SOURCE & SS & DF & MS & $F$ & SIGNIFICANCE \\
$\begin{array}{l}\text { Within } \\
\text { Cells }\end{array}$ & 5.43 & 90 & .06 & & \\
Interaction & .26 & 9 & .03 & .48 & .886 \\
\hline
\end{tabular}


APPENDIX G-5.

Repeated Measures Two Way Analysis of Covariance Summary Table for Skin Heat Conductance.

\begin{tabular}{llllll} 
SOURCE & SS & DF & MS & F & SIGNIFICANCE \\
$\begin{array}{l}\text { Within } \\
\text { Cells }\end{array}$ & 707.31 & 9 & 78.26 & & \\
Caffeine & 128.30 & 1 & 128.30 & 1.64 & .232 \\
\hline
\end{tabular}

\begin{tabular}{llllll} 
SOURCE & SS & DE & MS & $F$ & SIGNIFICANCE \\
$\begin{array}{l}\text { Within } \\
\text { Celis }\end{array}$ & 2624.31 & 90 & 29.16 & & \\
Time & 45701.29 & 9 & 5077.92 & 174.05 & .000 \\
\hline
\end{tabular}

\begin{tabular}{llllll} 
SOURCE & SS & DF & MS & F & SIGNIFICANCE \\
$\begin{array}{l}\text { Within } \\
\begin{array}{l}\text { Cells } \\
\text { Interaction }\end{array}\end{array}$ & 597.65 & 90 & 9 & 6.64 & \\
& 105.72 & 9 & 11.75 & 1.77 & .085 \\
\hline
\end{tabular}




\begin{tabular}{|c|c|c|c|c|}
\hline 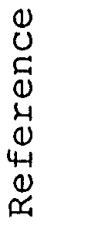 & 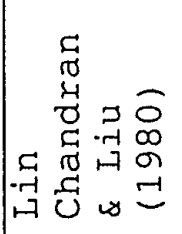 & 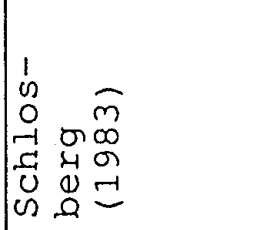 & & 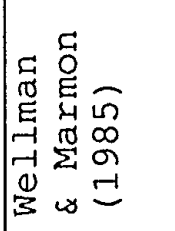 \\
\hline 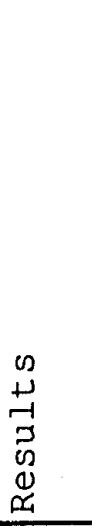 & 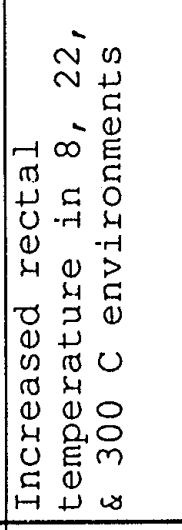 & 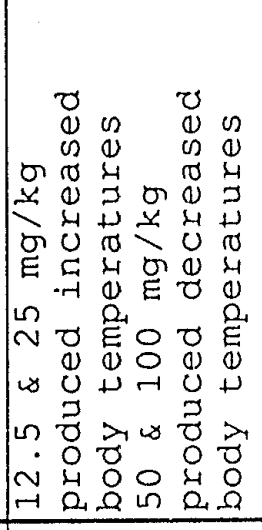 & 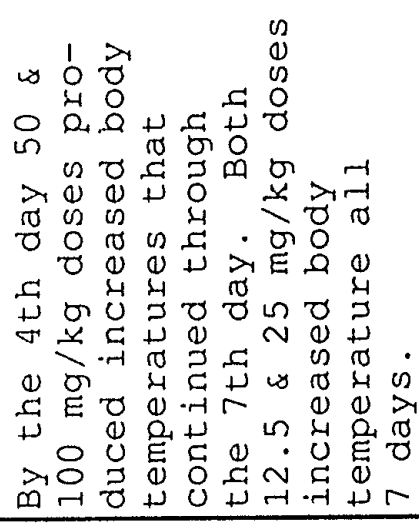 & 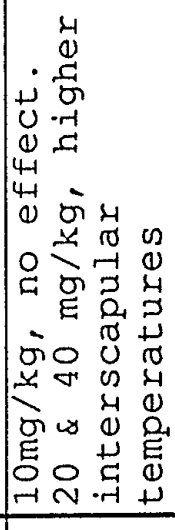 \\
\hline $\begin{array}{c}0 \\
0 \\
0 \\
-1 \\
0 \\
4 \\
0 \\
x \\
x \\
1\end{array}$ & 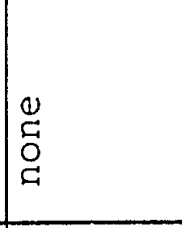 & 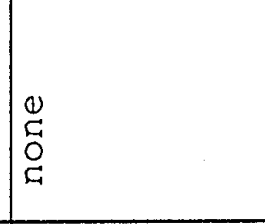 & & 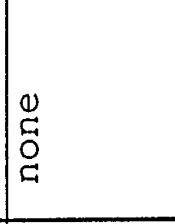 \\
\hline $\begin{array}{l}0 \\
0 \\
0 \\
0 \\
. \\
0 \\
0 \\
\vdots \\
0 \\
0\end{array}$ & $\mid \begin{array}{l}\vec{\alpha} \\
\widetilde{\alpha}\end{array}$ & 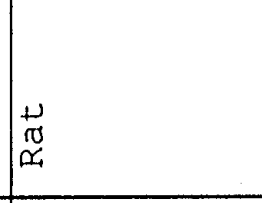 & $\begin{array}{l}\tilde{0} \\
\tilde{\alpha}\end{array}$ & 崩 \\
\hline 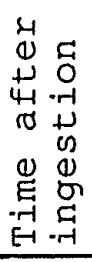 & 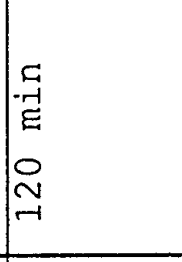 & 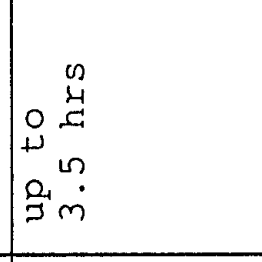 & 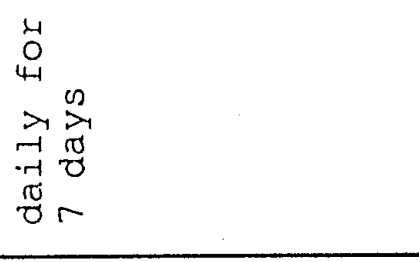 & 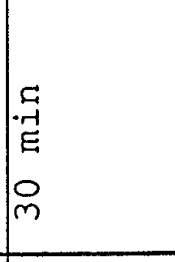 \\
\hline 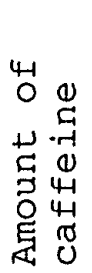 & 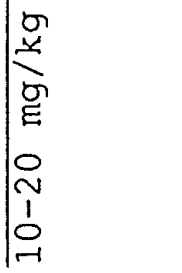 & 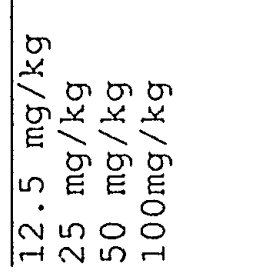 & 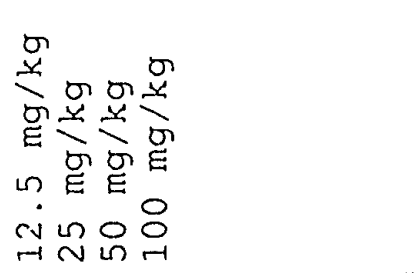 & |r \\
\hline
\end{tabular}




\begin{tabular}{|c|c|c|c|}
\hline 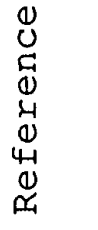 & 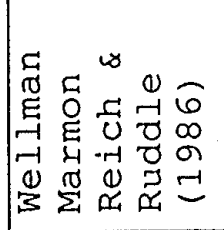 & $\begin{array}{ll}\dot{y} & \\
0 & 0 \\
0 & \infty \\
C & 0 \\
-7 & 0 \\
3 & =\end{array}$ & 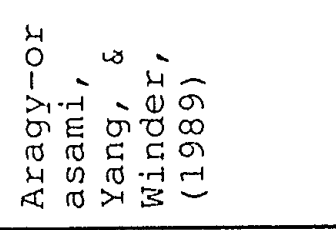 \\
\hline $\begin{array}{l}0 \\
\stackrel{1}{1} \\
\vdots \\
0 \\
0 \\
0 \\
\end{array}$ & 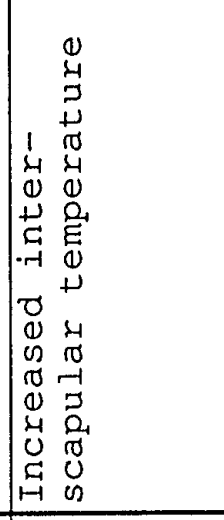 & 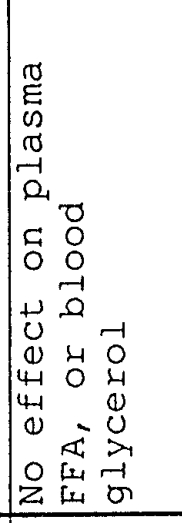 & 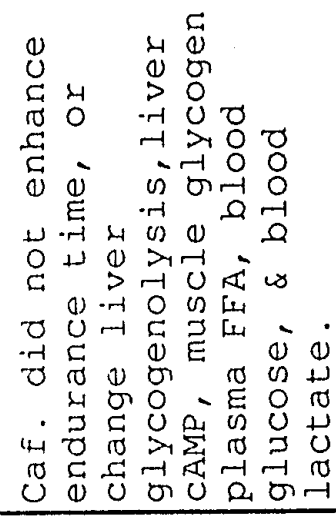 \\
\hline 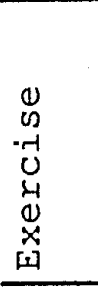 & 足 & 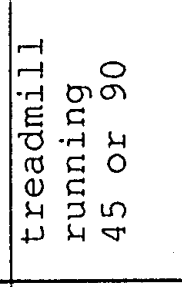 & 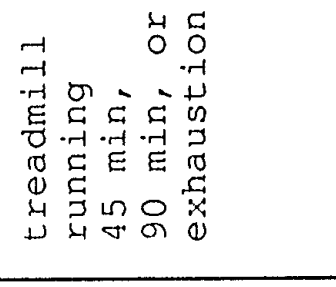 \\
\hline $\begin{array}{l}0 \\
1 \\
0 \\
0 \\
0 \\
0 \\
0 \\
0 \\
0\end{array}$ & $\begin{array}{l}+\vec{\omega} \\
\tilde{\alpha}\end{array}$ & $\begin{array}{l}\omega \\
\sigma \\
\sim\end{array}$ & 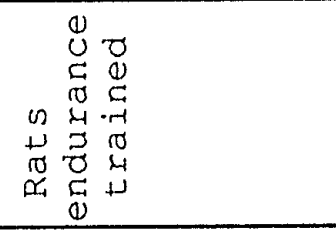 \\
\hline 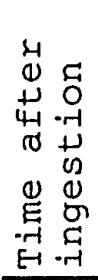 & 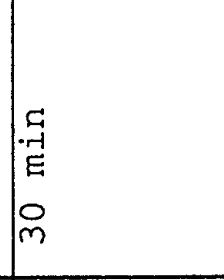 & 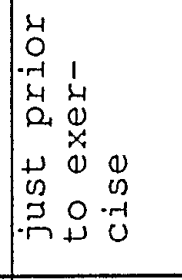 & 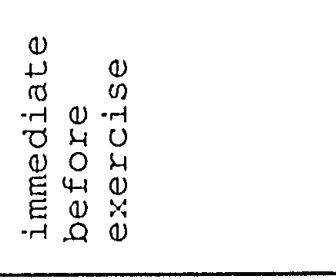 \\
\hline 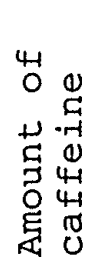 & 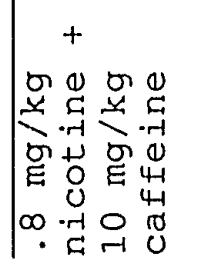 & 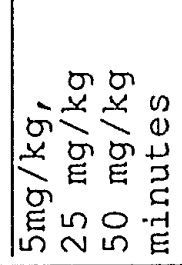 & 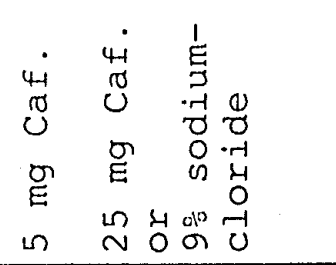 \\
\hline
\end{tabular}




\begin{tabular}{|c|c|c|c|c|c|}
\hline$n$ & $\begin{array}{l}0 \\
0 \\
0 \\
0 \\
0 \\
0 \\
0 \\
4-1 \\
0 \\
0\end{array}$ & 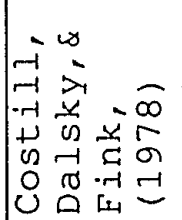 & 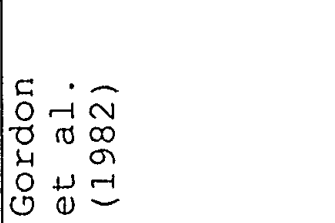 & 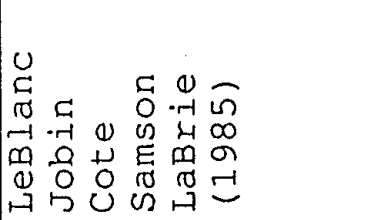 & 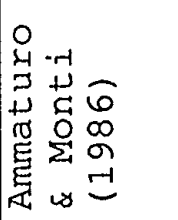 \\
\hline 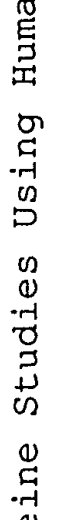 & $\begin{array}{l}0 \\
+1 \\
+1 \\
7 \\
0 \\
0 \\
0 \\
01\end{array}$ & 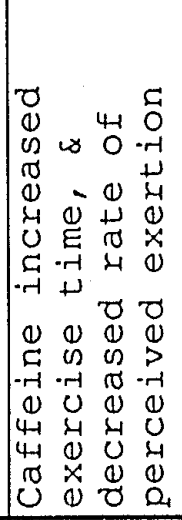 & 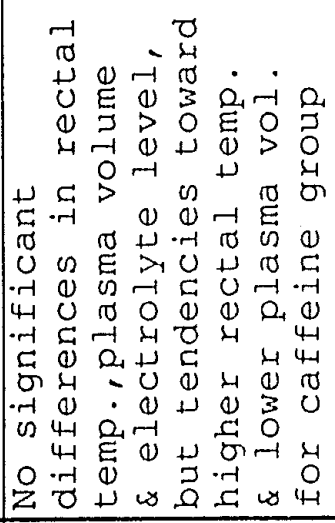 & 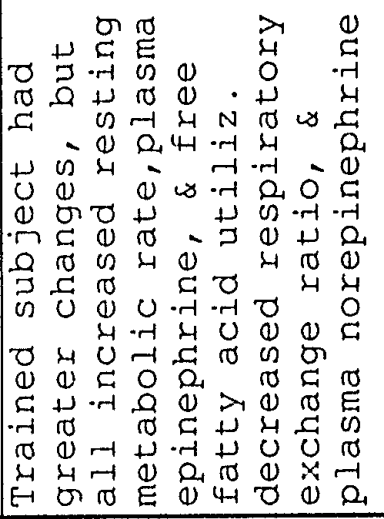 & 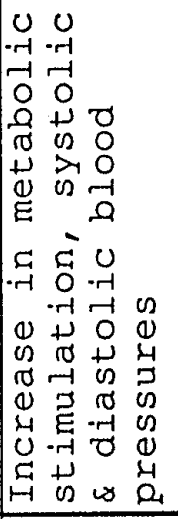 \\
\hline 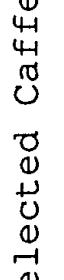 & $\begin{array}{c}0 \\
0 \\
0 \\
-1-1 \\
0 \\
4 \\
0 \\
0 \\
x \\
0.1\end{array}$ & 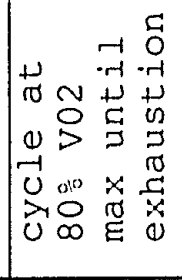 & 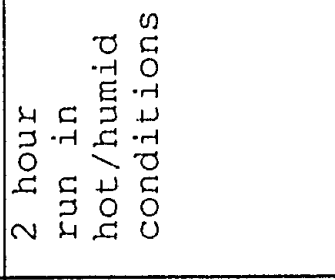 & 竞 & $\mid \begin{array}{l}0 \\
\text { C } \\
\text { O } \\
\text { C }\end{array}$ \\
\hline $\begin{array}{c}0 \\
\omega \\
E \\
0 \\
4 \\
4-1 \\
0 \\
-1\end{array}$ & $\begin{array}{l}0 \\
1 \\
0 \\
0 \\
1 \\
0 \\
0 \\
3 \\
0 \\
\end{array}$ & 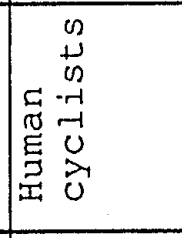 & 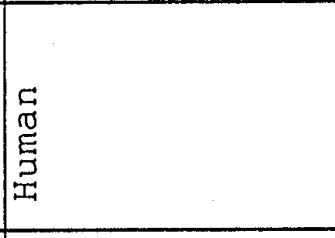 & 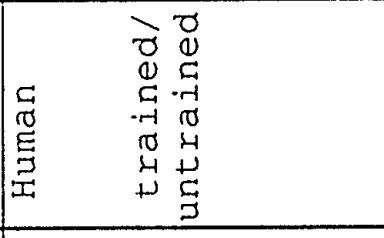 & 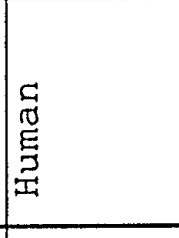 \\
\hline 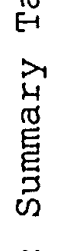 & 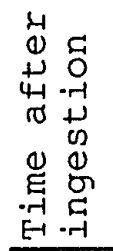 & 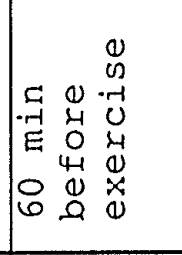 & 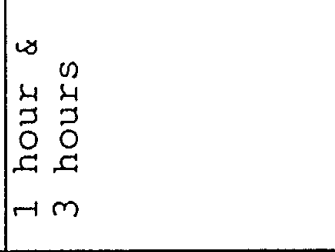 & $\mid \begin{array}{ll}O & n \\
H & \underline{4} \\
0 & \sim\end{array}$ & $\begin{array}{l}0 \\
\mu \\
. \\
\sim \\
\infty \\
-1\end{array}$ \\
\hline 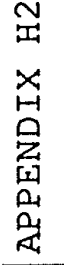 & 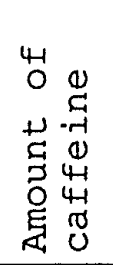 & $\begin{array}{l}9 \\
\mathrm{E} \\
0 \\
0 \\
m \\
i\end{array}$ & 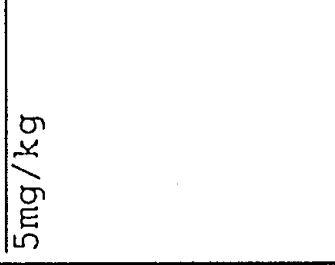 & 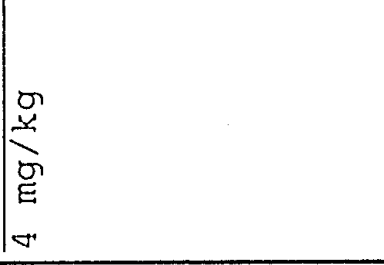 & 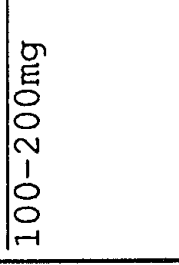 \\
\hline
\end{tabular}




\begin{tabular}{|c|c|c|c|c|}
\hline 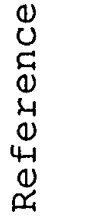 & $\begin{array}{cc}4 & 0 \\
0 & 6 \\
-1 & \infty \\
-1 & 0 \\
-\pi 1 & 0 \\
\Sigma & 0\end{array}$ & 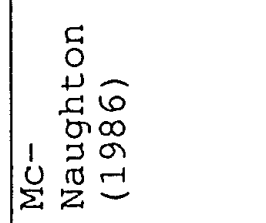 & 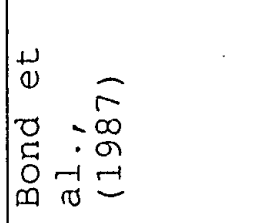 & 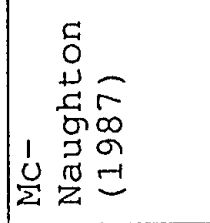 \\
\hline $\begin{array}{l}0 \\
\stackrel{1}{1} \\
-1 \\
3 \\
0 \\
0 \\
\simeq\end{array}$ & 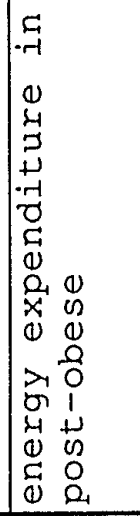 & 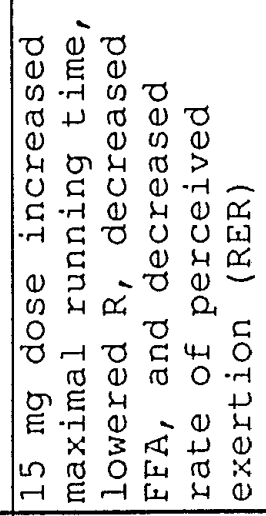 & 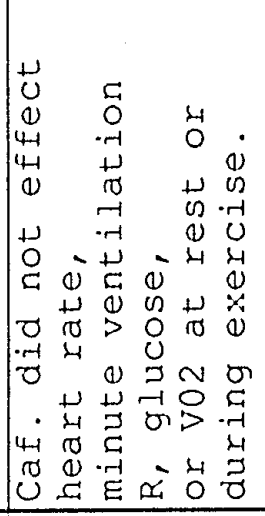 & 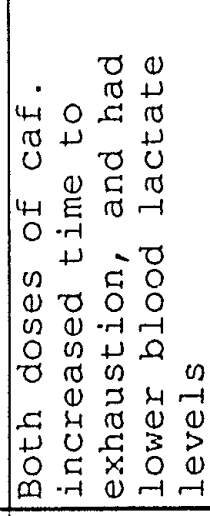 \\
\hline $\begin{array}{l}0 \\
0 \\
-1 \\
0 \\
0 \\
0 \\
0 \\
x \\
0\end{array}$ & & 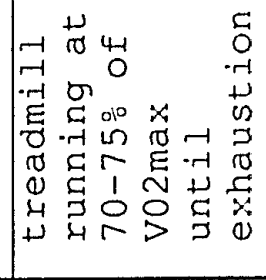 & 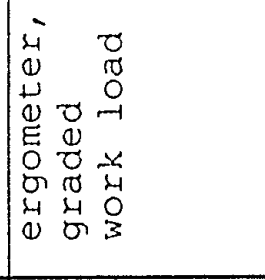 & 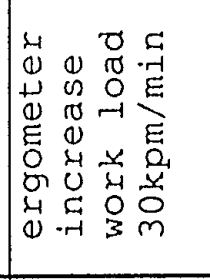 \\
\hline $\begin{array}{l}0 \\
+1 \\
0 \\
0 \\
.0 \\
0 \\
0 \\
0\end{array}$ & $\begin{array}{lll} & 1 & 0 \\
c & 1 & 0 \\
0 & 0 & 0 \\
0 & 0 & 0 \\
-1 & 0 & 0\end{array}$ & 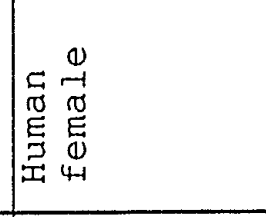 & 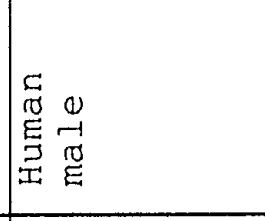 & 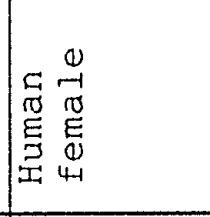 \\
\hline 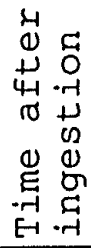 & & 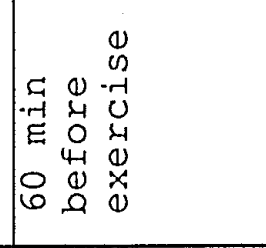 & 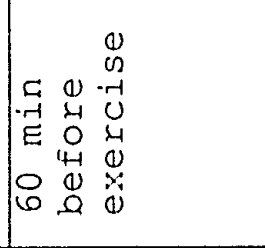 & 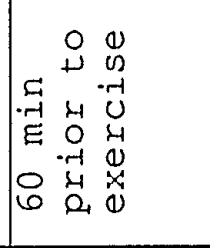 \\
\hline 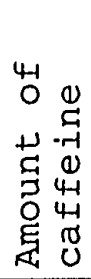 & 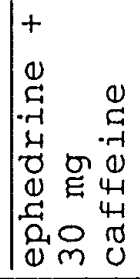 & 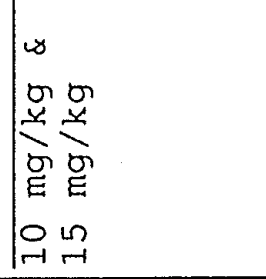 & $\mid \begin{array}{l}4-1 \\
0 \\
0 \\
0 \\
g \\
0 \\
0\end{array}$ & 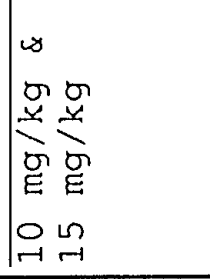 \\
\hline
\end{tabular}




\begin{tabular}{|c|c|c|c|}
\hline 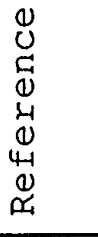 & 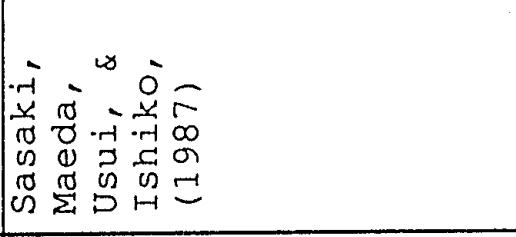 & 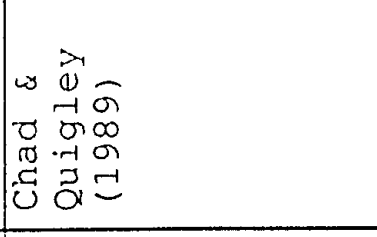 & $\begin{array}{ccc}0 & -1 & \sigma \\
-1 & 0 & \infty \\
-1 & 0 \\
3 & 4 & \ddots 1 \\
0 & 0 & \end{array}$ \\
\hline 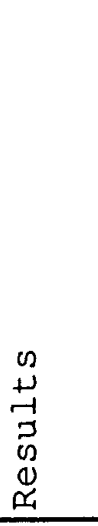 & 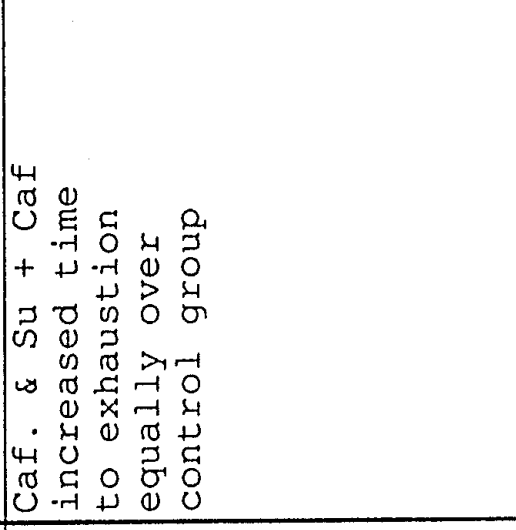 & 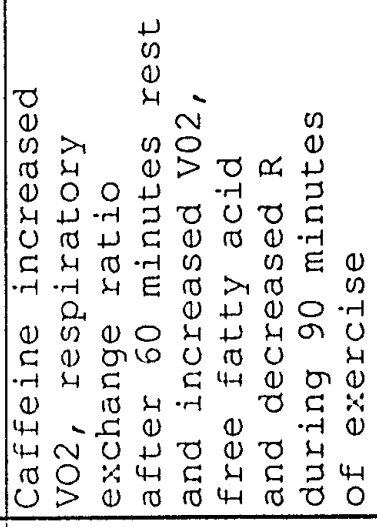 & 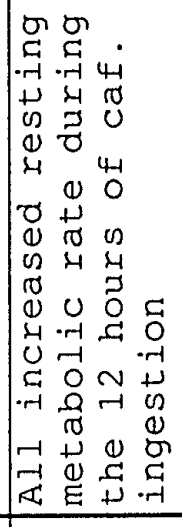 \\
\hline 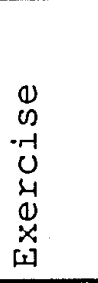 & 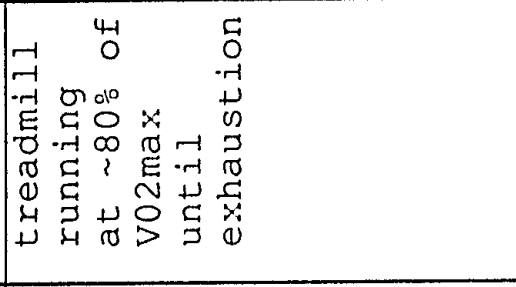 & 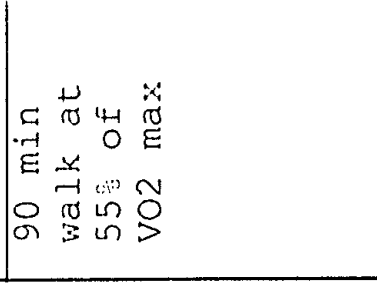 & 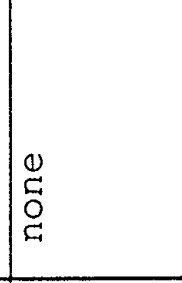 \\
\hline $\begin{array}{l}0 \\
1 \\
0 \\
0 \\
0 \\
0 \\
0 \\
0 \\
0 \\
0\end{array}$ & 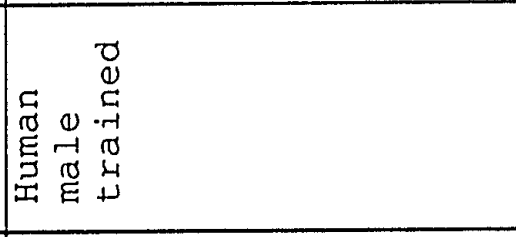 & 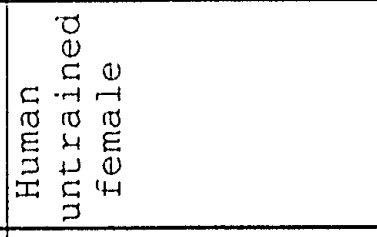 & 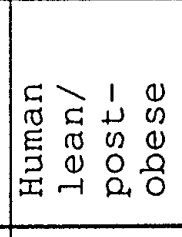 \\
\hline 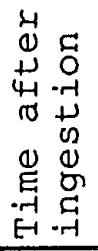 & 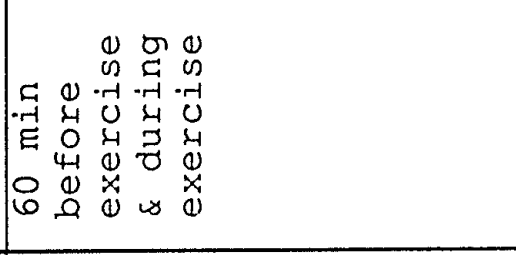 & 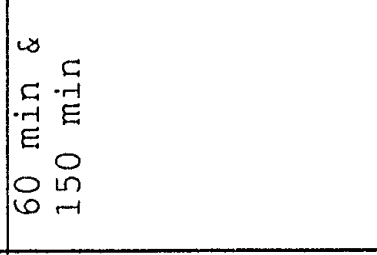 & 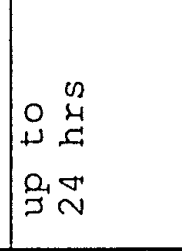 \\
\hline 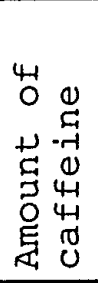 & 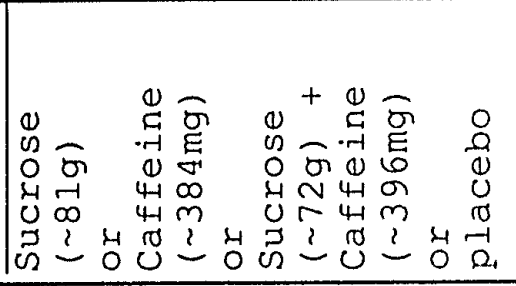 & $\mid \begin{array}{l}0 \\
\dddot{y} \\
\text { En } \\
\text { E } \\
\text { n }\end{array}$ & 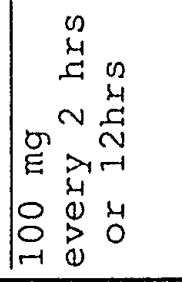 \\
\hline
\end{tabular}




\begin{tabular}{|c|c|c|c|c|c|}
\hline 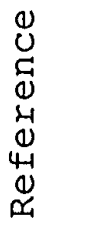 & 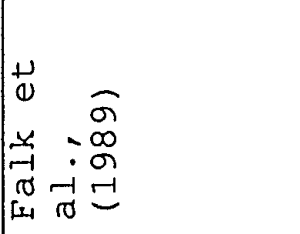 & 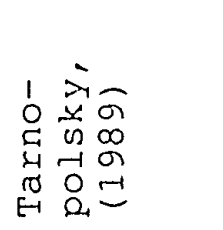 & \multicolumn{2}{|l|}{ 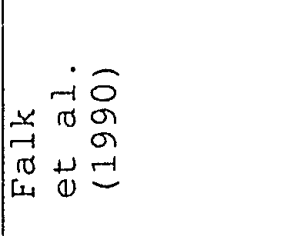 } & 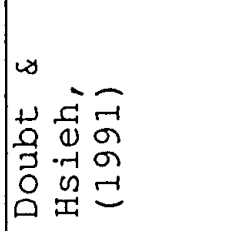 \\
\hline $\begin{array}{l}0 \\
+ \\
-1 \\
3 \\
0 \\
0 \\
0 \\
0\end{array}$ & 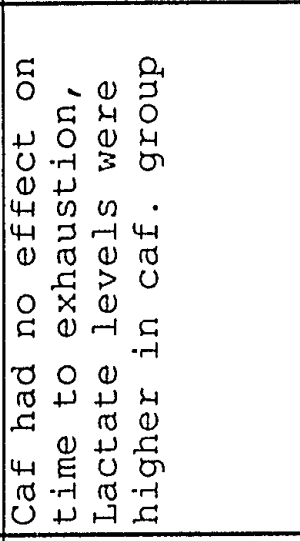 & 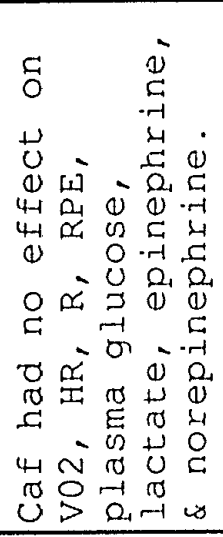 & 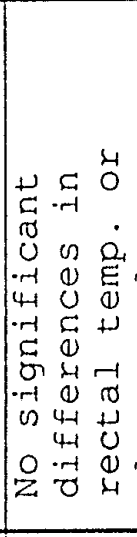 & 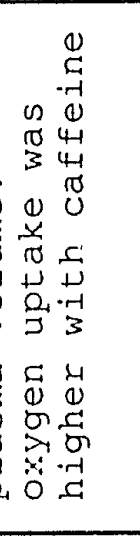 & 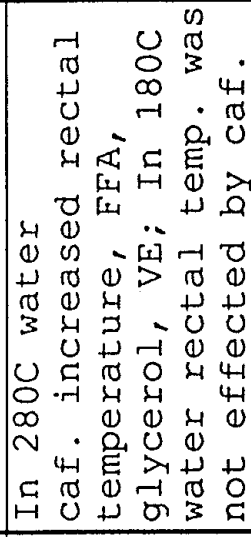 \\
\hline $\begin{array}{l}0 \\
0 \\
-1 \\
0 \\
.4 \\
0 \\
0 \\
x \\
a\end{array}$ & 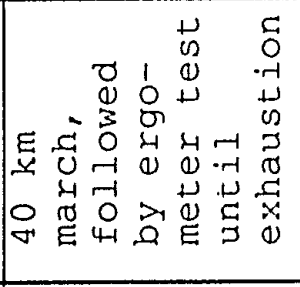 & 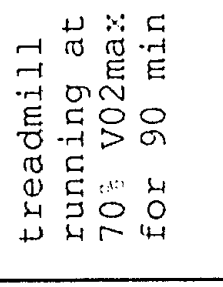 & 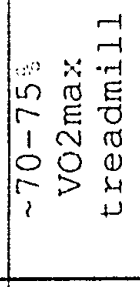 & & 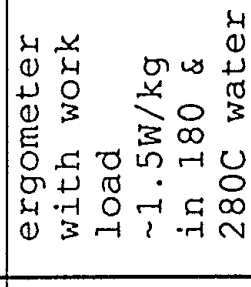 \\
\hline $\begin{array}{l}0 \\
+0 \\
0 \\
. \\
0 \\
0 \\
0 \\
0\end{array}$ & 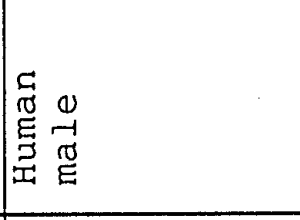 & 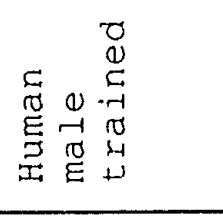 & 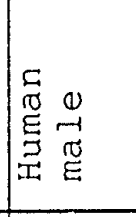 & & 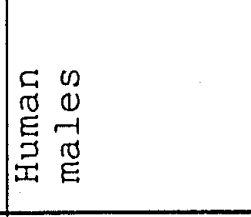 \\
\hline 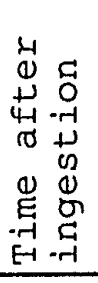 & 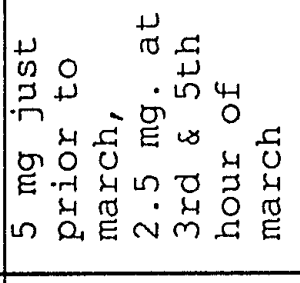 & 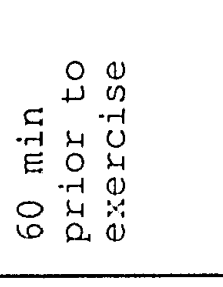 & 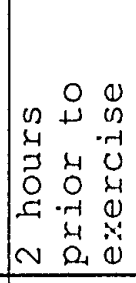 & 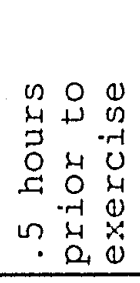 & 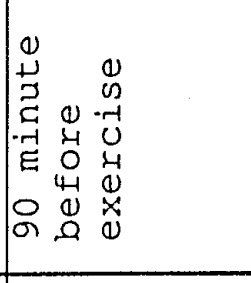 \\
\hline 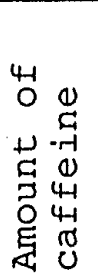 & 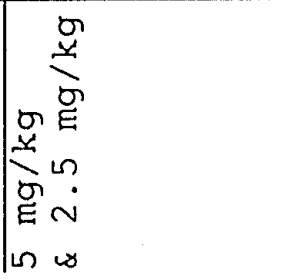 & $\begin{array}{l}\frac{D}{y} \\
\frac{\mathscr{V}}{E} \\
6\end{array}$ & 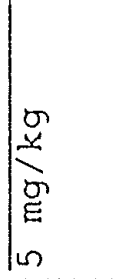 & $\begin{array}{l}\stackrel{G}{y} \\
\stackrel{g}{G} \\
\text { E } \\
\text { Ln } \\
\dot{N}\end{array}$ & $\mid \begin{array}{l}\sigma \\
\dddot{y} \\
\bar{g} \\
\Xi \\
0\end{array}$ \\
\hline
\end{tabular}




\begin{tabular}{|c|c|c|}
\hline 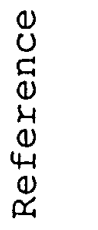 & 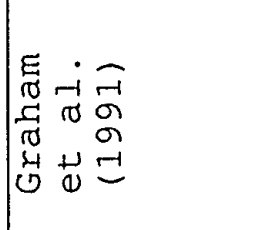 & 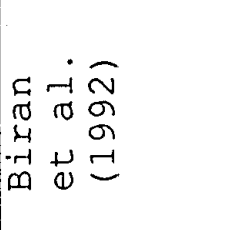 \\
\hline 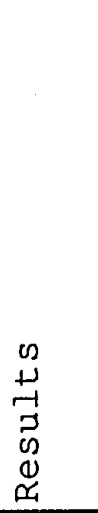 & 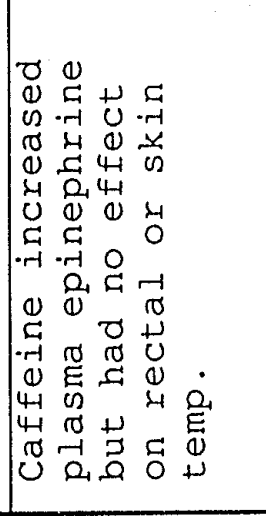 & 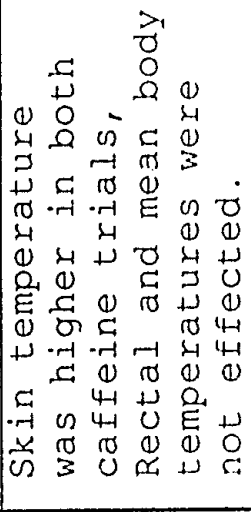 \\
\hline 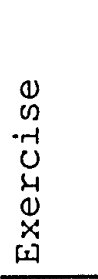 & 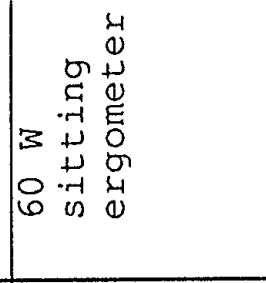 & 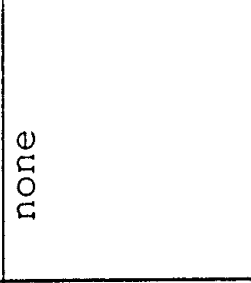 \\
\hline $\begin{array}{l}0 \\
+1 \\
0 \\
0 \\
0 \\
0 \\
0 \\
0 \\
0\end{array}$ & 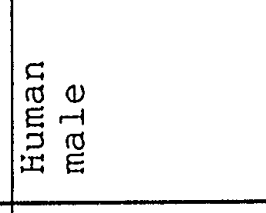 & 忘 \\
\hline 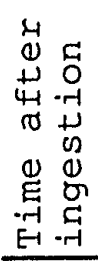 & 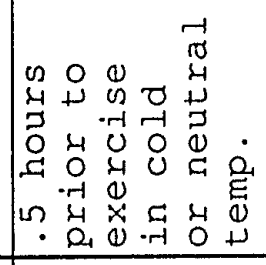 & 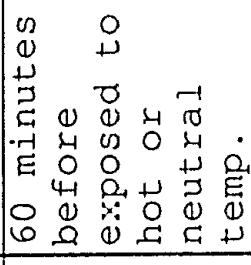 \\
\hline $\begin{array}{ll}41 & 0 \\
0 & 0 \\
4 & -7 \\
5 & 0 \\
7 & 4 \\
0 & 4 \\
5 & 0 \\
5 & 0\end{array}$ & 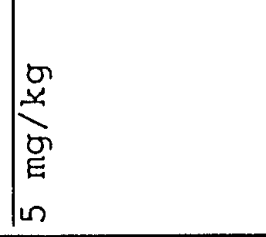 & 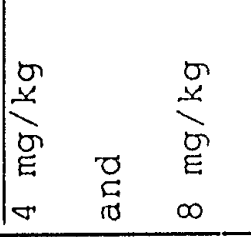 \\
\hline
\end{tabular}

